\title{
Evolutionary coexistence in a fluctuating environment by specialization on resource level
}

\author{
Meike T. Wortel ${ }^{1, *}$ \\ ${ }^{1}$ Molecular Microbiology and Microbial Food Safety, Swammerdam Institute for Life Sciences, \\ University of Amsterdam, Amsterdam, The Netherlands \\ *m.t.wortel@uva.nl
}

\begin{abstract}
Microbial communities in fluctuating environments can contain many species and diversity within species, both in natural environments such as the human gut, and in laboratory settings when communities are propagated for a long time. Whether this diversity is at the species level, within the species level, or a combination of both, the question remains: what processes lead to the origination and maintenance of this diversity?

When nutrient levels fluctuate over time, one possibly relevant process is that different types specialize on low and high nutrient levels. The relevance of this process is supported by observations of types co-existing through this mechanism when put together in the laboratory, and by simple models, that show that negative frequency dependence of two types, specialized on low and high resource level, can stabilize coexistence. However, when microbial populations are in an environment for a long time, they evolve. In this article we determine what happens when species can evolve; whether branching can occur to create diversity and whether evolution will destabilize coexistence.

We find that for the trade-off data between growth at low and high substrate concentrations, available for the bacterium Escherichia coli and the yeast Saccharomyces cerevisiae on glucose, there is only a small portion of the trait-space that allows for coexistence. Moreover, this coexistence is destabilized by evolution, and the only evolutionary stable outcome is a single type. When we combine two species that are well-adapted on their own, we do find that they can form an evolutionary singular coalition, i.e. a coexistence that is evolutionarily stable. We conclude that although specialization on resource level can support diversity within a species, it is likely not a cause by itself. In contrast, for species consortia this specialization can lead to evolutionarily stable coexistence.
\end{abstract}

\section{Introduction}

Bacterial species are very abundant on almost all places on earth. Classical theory predicts that only as many species can coexist as there are resources. However, in some environments, many more species coexist than there are resources. Recently, the existence of a much higher diversity was observed, as different strains of the same species can exist for long timescales. This happens in complicated environments such as the human gut microbiome ${ }^{1,2}$. More surprisingly, even in laboratory environments, where the environment is simplified as much as possible, we see that long-term coexistence of different clades is very widespread, such as in the long term evolution experiment (LTEE) by Lenski and coworkers ${ }^{3}$. Several explanations have been given for the coexistence of strains: cross-feeding and specialization on different resources. Because of the fluctuating resource levels, the questions remains if only specialization on the different resource levels can already explain a part of the diversity we observe. This paper investigates the theoretical possibility of evolutionary coexistence of different strains and species on fluctuating resource levels.

The first observation of coexistence of two strains in an environment with a fluctuating resource level is by Levin ${ }^{4}$. With a mathematical toy model they showed that, when one species takes up nutrients faster at low resource levels and the other at high, coexistence is possible ${ }^{5}$. An extension of the model with fixed cycle lengths and lag phases also shows possibilities of coexistence ${ }^{6}$. In a different experiment, Turner et al. ${ }^{7}$ observed coexistence and found evidence of a trade-off on growth at different resource levels, but a mathematical model showed that this was not enough to sustain coexistence. Closer analysis showed that indeed, in addition to the substrate specialization trade-off, there was cross-feeding between the strains. These studies are all restricted to analysing strains with fixed properties. To observe coexistence of cohabiting cells, the coexitence should have some evolutionary stability, e.g. adaptation should not lead to the loss of the coexistence.

Fitness in serial transfer cultures consist of many properties, such as lag phase, exponential growth rate, substrate limited growth and death rate. Manhart et al. ${ }^{8}$ studies lag phase and exponential growth rate and the evolutionary consequences, such as coexistence and bi-stability and provides a theoretical frame-work for incorporating such measurements. They focus on competitions of sets of strains, and less on evolutionary trajectories.

Coexistence in fluctuating environments by specialization on resource level has been studied and observed, but those papers assume stable properties of the different species, leading to 'ecological coexistence'. This implies that as long as the species do not adapt, they will coexist. However, microorganisms often grow fast 
bioRxiv preprint doi: https://doi.org/10.1101/2021.05.18.444718; this version posted September 2, 2021. The copyright holder for this preprint (which was not certified by peer review) is the author/funder, who has granted bioRxiv a license to display the preprint in perpetuity. It is made available under aCC-BY 4.0 International license.

$\mathbf{A}$
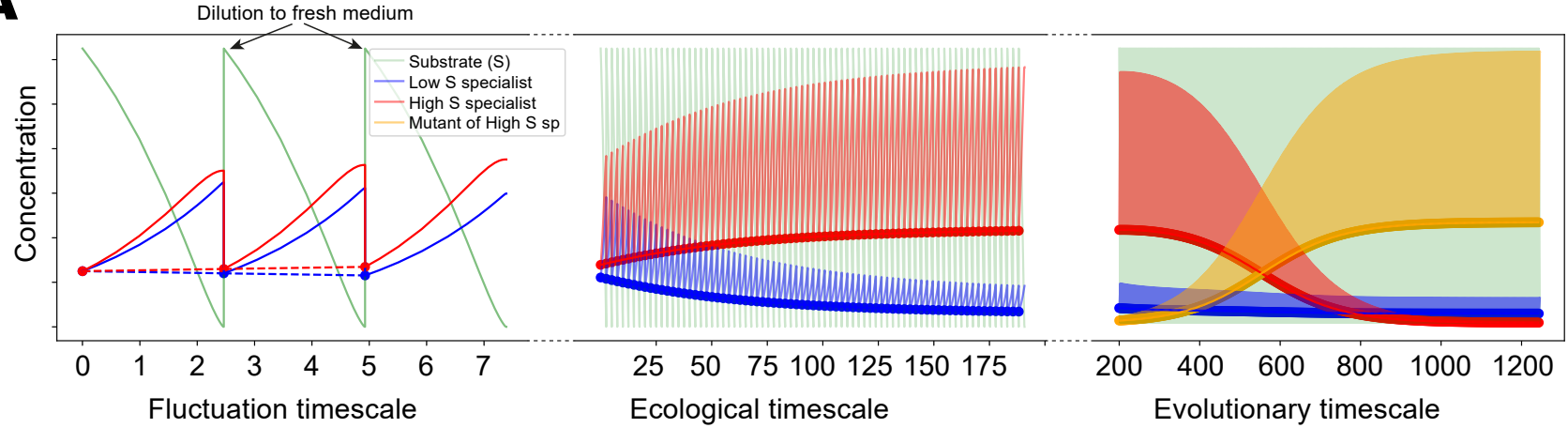

B
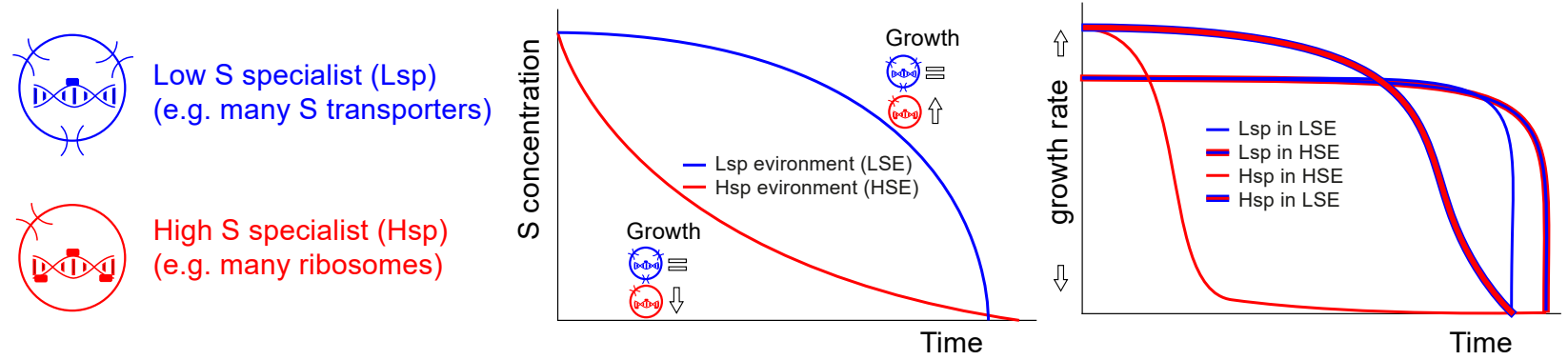

Figure 1: A The dynamics of serial transfer experiments. On fast 'fluctuation timescales', the species densities and metabolite concentrations are continuously changing. However, over ecological timescales a stability can arise, where the concentrations at the beginning of each transfer, just after dilution, stay constant over time. However, over evolutionary timescales, strains can change in their properties, e.g. with the occurrence of mutants that take over the population and displace either one of the strains and form a new 'ecologically stable' coexistence (as in the figure) or both strains. B There is negative frequency dependent selection between low substrate (S) specialists and high substrate specialists. Those different specializations can arise e.g. from different protein allocations. Low substrate specialists have a higher affinity (lower $k_{S}$ ), lower maximum growth rate $\left(\mu_{\max }\right)$ and a lower value for the in this paper introduced normalized substrate specialization parameter $u$ than high substrate specialists. When low substrate specialists are abundant, the substrate concentration decreases slower but is completely depleted faster than when high substrate specialists are abundant (blue vs red line in middle panel). Low substrate specialists are not influenced greatly by the substrate concentration, but high substrate specialists thrive under the high substrate concentrations that are around for longer when low substrate specialists are abundant. Therefore high substrate specialists keep a higher growth rate for longer in an environment with low substrate specialists (red line with blue edges in right panel), than in an environment with high substrate specialists (red line in right panel). Similarly, low substrate specialists keep growing longer in an environment with high substrate specialists, because it takes longer for the substrate to be completely depleted (blue line with red edges vs blue line).

and are in large numbers, therefore there is abundant opportunity for adaptation. The assumption that species do not change is not very realistic and it is important to look at the 'evolutionarily stable coexistence', where selection on the traits of the different species does not lead to loss of the coexistence. This study addresses the evolutionary trajectories and outcomes in fluctuating environments. To study evolutionary coexistence we need to have knowledge about the possible attainable phenotypes and subsequently use methods that can predict evolutionary trajectories. Here we use adaptive dynamics to investigate the evolutionary coexistence of different strains or species specialized on resource level in a fluctuating environment.

In this paper, we study evolutionary trajectories, not only fixed strains, using trade-offs supported by experimental data. We focus on growth at different resource levels, which is a nonlinear property (instead of e.g. yield and lag-time), and therefore mathematically more difficult to analyse. First, we show an analytical derivation of the selection pressure. Then, we investigate the evidence and formulas for experimental trade-offs between maximal growth rate and affinity. Next, we study the possible ecological coexistence for such strains and finally evolutionary coexistence, including consortia of multiple species.

\section{Model description}

The model simulates an environment where the resource is consumed, and at the moment the resource is completely consumed, cells are diluted to a fixed population size and new resource is added. This relates to the conditions that are usually used for experimental evolution, but there are some simplifications. In those conditions cells usually have 4 phases: (1) lag phase, (2) exponential growth, (3) low-nutrient growth and (4) stationary phase $^{9}$. In this paper we only focus on the growth phases (2) and (3).

We assume Monod-growth and calculate the growth over a complete batch cycle. In this way we can calculate the selection gradient and we link this to experiments with a serial transfer set-up. 
bioRxiv preprint doi: https://doi.org/10.1101/2021.05.18.444718; this version posted September 2, 2021. The copyright holder for this

preprint (which was not certified by peer review) is the author/funder, who has granted bioRxiv a license to display the preprint in perpetuity. It is made available under aCC-BY 4.0 International license.

\subsection{Basic model}

First we describe the model for one species ( $x$ in concentration) and one substrate ( $s$ in concentration). We assume Monod growth with a monod constant (or (substrate) affinity) $k_{S}$ (in concentration) and a maximal growth rate $\mu_{\max }$ (in $1 /$ time). The numerical yield of the species $x$ on the substrate $s$ is $Y_{X / S}$. This leads to the dynamical system:

$$
\begin{aligned}
\frac{d x(t)}{d t} & =\mu_{\max } \frac{s(t)}{k_{S}+s(t)} x(t) \\
\frac{d s(t)}{d t} & =-\frac{1}{Y_{X / S}} \mu_{\max } \frac{s(t)}{k_{S}+s(t)} x(t)
\end{aligned}
$$

To enhance readability for the derivations, we will use a notation where we write $s$ and $x$ for $s(t)$ and $x(t)$, $\mu$ for $\mu_{\max }, k$ for $k_{S}$ and $y$ for $Y_{X / S}$ :

$$
\begin{aligned}
& \frac{d x}{d t}=\mu \frac{s}{k+s} x \\
& \frac{d s}{d t}=-\frac{1}{y} \mu \frac{s}{k+s} x
\end{aligned}
$$

When we have multiple species or strains (we will call them types), the systems for $n$ types becomes:

$$
\begin{aligned}
\frac{d x_{i}}{d t} & =\mu_{i} \frac{s}{k_{i}+s} x_{i} \\
\frac{d s}{d t} & =-\sum_{i=1}^{n} \frac{1}{y_{i}} \mu_{i} \frac{s}{k_{i}+s} x_{i}
\end{aligned}
$$

\subsection{Growth conditions, fitness and selection gradient}

We study the conditions where periodically substrate is added to the system, and cells are diluted to a fixed concentration. To focus solely on the growth phases, we study the system until the substrate runs out, and we stop when $s(t)$ approaches 0 . This is equivalent to transferring at long enough timescales such that all substrate is consumed, when there is no death at stationary phase. In some conditions, death at stationary phase is observed, and trade-offs between death rate and for example maximal growth rate are possible, but here we want to isolate the effects of only the growth phases.

Initially, we start every cycle of substrate addition with $s(0)=s_{0}$ and $\sum_{i=1}^{n} x_{i}(0)=x_{0}$. Selection here acts on the increase of growth over a full cycle. We therefore define the final concentration divided by the initial concentration $\left(x_{i, \infty} / x_{i, 0}\right)$ as the growth factor. For one type, at the end of the growth $s(t=e n d)=0$ and $x(t=e n d)=x_{0}+y s_{0}$ and therefore the growth factor is equal to $\frac{x_{0}+y s_{0}}{x_{0}}$.

When we define the fitness, we have to assess the growth factor of a mutant $\left(x^{*}\right)$ with a different monod constant $\left(k^{*}\right)$, maximal growth rate $\left(\mu^{*}\right)$ and/or yield $\left(y^{*}\right)$. If the mutant has a higher growth factor than the resident $(x)$, the mutant increases in relative abundance and will be able to invade. More precisely, a mutant can invade when:

$$
\frac{x^{*}(\infty)}{x^{*}(0)}>\frac{x(\infty)}{x(0)}
$$

We define the fitness $(W)$ of the mutant (similar to e.g. Wiser et al. ${ }^{10}$ ) as:

$$
W=\frac{\log \left(x_{\infty}^{*} / x_{0}^{*}\right)}{\log \left(x_{\infty} / x_{0}\right)}
$$

The log is commonly used to compensate for exponential growth, but does not affect the fact that strains with $W>1$ can invade. In evolutionary analysis, the selection coefficient is used. The selection coefficient $\omega$ (commenly called $s$ but here denoted with $\omega$ to avoid confusion with the substrate concentration) is defined as $W-1$ and therefore a selection coefficient of 0 means that a mutant is not selected for or against (this is equivalent to the definition of $\omega=\ln \left(x_{\infty}^{*} / x_{\infty}\right)-\ln \left(x_{0}^{*} / x_{0}\right)^{11}$ also used in $\left.{ }^{12}\right)$. Strains with positive selection coefficients in a resident population will increase in number when rare, and can invade.

By studying the effect of the different phenotypes (in our case $\mu, k$ and $y$ ) on the fitness, we can calculate the selection gradient (see Appendix Section A.4). The definition of the selection gradient $\left(S_{X}\right)$ of a property $X$ is $\left(\operatorname{as~in~}^{9}\right)$ :

$$
S_{X}=\frac{X}{W} \frac{\partial W}{\partial X}
$$

\subsection{Evolutionary optimum, evolutionarily stable strategies (ESS) and evo- lutionarily singular coalitions (ESC)}

Since the properties of a type define the ecological properties, in this case the substrate level over time, we cannot directly define the evolutionary optimum. According to evolutionary game theory, we define the optimum here as the evolutionarily stable strategy (ESS). Therefore we look at a strategy $(\mu, k, y)$ that cannot be invaded by any other strategy (there is no strategy with a positive selection coefficient: $\left.\nexists\left(\mu^{*}, k^{*}, y^{*}\right): \omega>0\right)$. When the 
bioRxiv preprint doi: https://doi.org/10.1101/2021.05.18.444718; this version posted September 2, 2021. The copyright holder for this preprint (which was not certified by peer review) is the author/funder, who has granted bioRxiv a license to display the preprint in perpetuity. It is made available under aCC-BY 4.0 International license.

properties are unbounded, there is no ESS, but in practice the properties are bounded and correlated. Tradeoffs between these properties can lead to an evolutionarily stable strategy or evolutionarily singular coalitions. Although in theory, evolutionarily singular coalitions of more than two types are possible, the scenarios discussed in this paper will never lead to such coalitions, and therefore we further restrain to coalitions of two types.

Stable coexistence requires frequency dependent selection, i.e. when one type becomes more abundant, selection will push the other type to become more abundant. In this system that would happen when one type specialises on high resource (high growth rate on high resource) and therefore reduces the high resource phase when abundant, while the other type specialises on low resource and reduces that phase when abundant (see Figure 1B). This leads to stable coexistence of the two types as long as there are no evolutionary changes, which I will further refer to as ecological coexistence.

When we do allow for evolutionary changes, ecological coexistence could become destabilized. When the coexistence is stable even under evolutionary changes, I will refer to it as evolutionary coexistence (termed 'evolutionarily stable coexistence' by Li et al. ${ }^{13}$ ), which leads to an evolutionarily singular coalition (ESC) defined in adaptive dynamics ${ }^{14}$. In this case a coalition is a collection of phenotypes, that can occur through evolutionary branching, but also through e.g. migration. We will use adaptive dynamics techniques to find conditions where we have ECSs. Traditionally, adaptive dynamics assumes an ecological timescale and an evolutionary timescale, and assumes the ecological timescale to be in steady state when assessing the evolutionary dynamics. In this system, the ecological timescale coincides with the dynamics over the coarse of many transfers. The evolutionary timescale where we assess property changes, assumes that the ecological timescale is in steady state, therefore the profile within a transfer is the same from transfer to transfer. Our system includes a third timescale, the fluctuation timescale, which encompasses the changes within a transfer (see Figure 1A).

\section{Results}

\subsection{Invasion fitness under fluctuating environments}

The invasion fitness $\left(W^{*}\right)$ of the mutant with a certain maximal growth rate $\left(\mu^{*}\right.$ or $\left.\mu_{\max }^{*}\right)$, substrate affinity $\left(k^{*}\right.$ or $\left.k_{S}^{*}\right)$ and numerical yield $\left(y^{*}\right.$ or $\left.Y_{X / S}^{*}\right)$ in an environment of residents (with corresponding properties $\mu$ or $\mu_{\max }, k$ or $k_{S}$ and $y$ or $Y_{X / S}$ ) is (see section A.2 for the derivation):

$$
W^{*}=\frac{\ln \left(x_{\infty}^{*} / x_{0}^{*}\right)}{\ln \left(x_{\infty} / x_{0}\right)}=\frac{\ln \left[\left(\frac{k^{*}+s_{0}}{k^{*}}\right)^{\frac{\mu^{*}}{\mu} \frac{k-k^{*}}{k^{*}+\frac{x_{0}}{y}+s_{0}}}\left(\frac{x_{0}+y s_{0}}{x_{0}}\right)^{\frac{\mu^{*}}{\mu} \frac{k+\frac{x_{0}}{y}+s_{0}}{k^{*}+\frac{x_{0}}{y}+s_{0}}}\right]}{\ln \left[\frac{x_{0}+y s_{0}}{x_{0}}\right]}
$$

If the mutant is the same as the resident $\left(\mu^{*}=\mu\right.$ and $\left.k^{*}=k\right)$, the growth factor (relative increase in population size) of the mutant $\left(\frac{x^{*}(\infty)}{x^{*}(0)}\right)$ is exactly that of the resident $\left(\frac{x_{0}+y s_{0}}{x_{0}}\right)$ and $W^{*}=1$, as expected. When only the maximal growth rates is different $\left(k^{*}=k\right.$ and $\left.\mu^{*} \neq \mu\right)$, the growth factor of the mutant is the growth factor of the resident to the power $\frac{\mu^{*}}{\mu}$ and the invasion fitness is $\frac{\mu^{*}}{\mu}$. The effect of a difference in substrate affinity $\left(k^{*} \neq k\right)$ is more complex (see Appendix Section A.4), as well as the effect of a trade-off between maximal growth and affinity (see Appendix Section A.3).

Whether strains with higher affinity or with higher maximal growth rate can invade depends on the conditions, such as the initial substrate concentration $\left(s_{0}\right)$ and the initial biomass $\left(x_{0}\right)$. A mutant with a higher maximal growth rate $\left(\mu^{*}\right)$ but a lower affinity (higher $k^{*}$ ) benefits from long periods of high nutrients, that is a high initial substrate $\left(s_{0}\right)$ and a low initial biomass $\left(x_{0}\right)$. Indeed, it follows from the above equation that a high $s_{0}$ leads to a relatively stronger effect of $\mu^{*}$ on the growth factor (and therefore a higher invasion fitness) while a high $x_{0}$ leads to a relatively larger effect of $k^{*}$ (see Appendix Section A.4).

The numerical yield is not relevant for the fitness of an invading strain, as we can scale the initial biomass $\left(x_{0}\right)$ with the yield and eliminate the yield. The growth rate might be affected by the yield, but that effect could be added as a tradeoff between the parameters $\mu, k$ and $y$ (as in Figure 2C). There is no selection on $y$, but any result that is affected by $x_{0}$ is inversely affected by $y$. Therefore, the yield of the resident strain does affect the fitness of other invading mutants.

For the evolutionary analysis we will use the selection coefficient $(\omega)$ instead of the invasion fitness (Eq (7)). Any strain with a positive selection coefficient can invade.

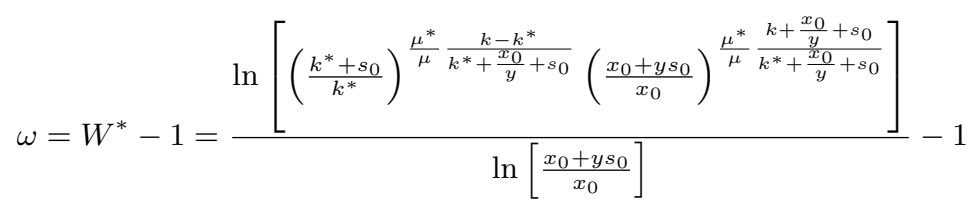

\subsection{Trade-off in growth parameters for Escherichia Coli and Saccharomyces Cerevisiae}

Evolutionary dynamics can be interesting when the growth properties are bounded, or when there is a trade-off between the properties. Since there is no selection on the numerical yield, we first investigate a trade-off between $\mu_{\max }$ and $k_{S}$. A possible mechanism behind this trade-off could be a protein investment trade-off, e.g. the cell can invest in transporters to improve growth on low resource levels or the cell can invest in ribosomes to 
A

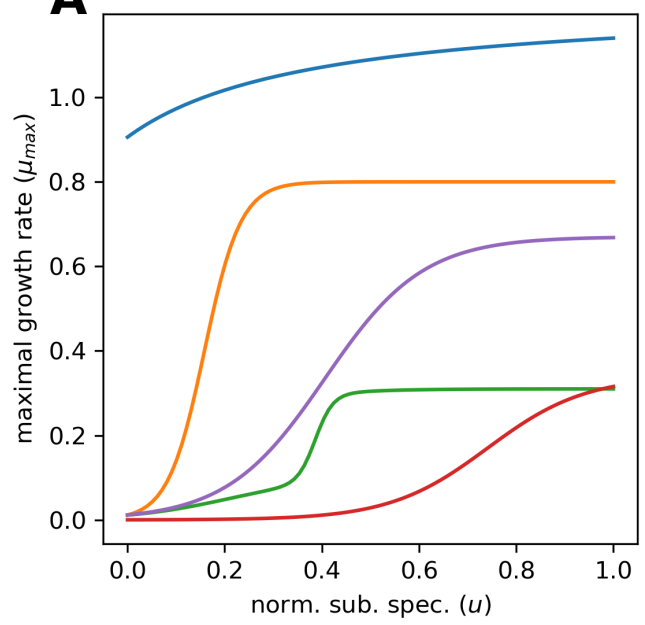

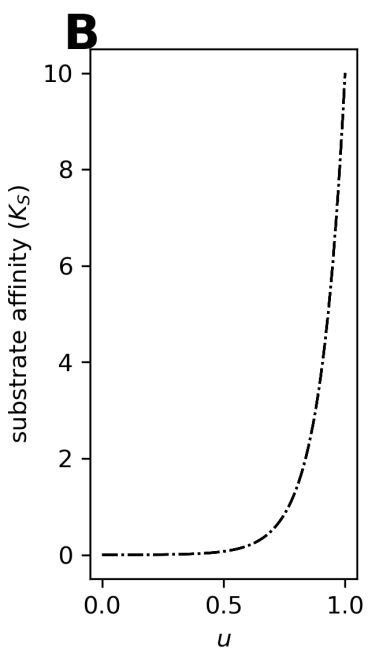

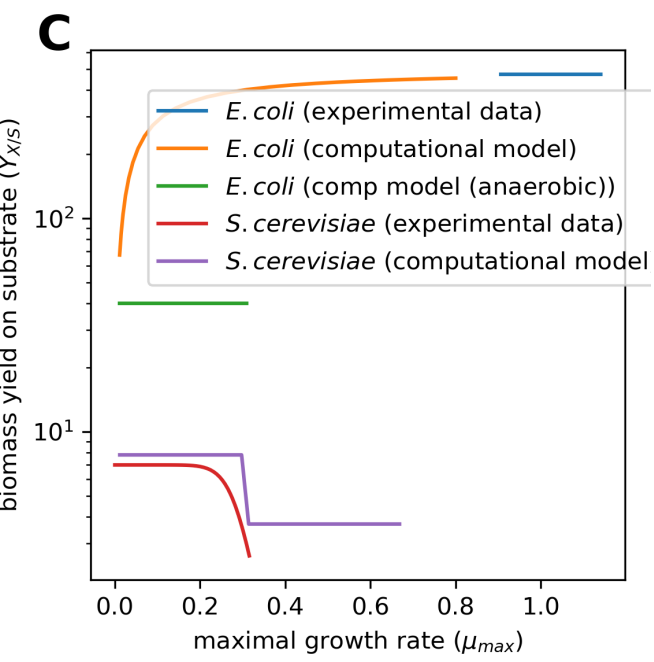

Figure 2: Trade-offs between growth parameters. A Trade-offs between $\mu_{\max }$ and $k_{S}$ shown by the dependency of $\mu_{\max }$ on the introduced normalized specialization parameter $u$, which scales logarithmically with $k_{S}$ (B and Equation (A.6)). C Trade-offs between $Y_{X / S}$ and $\mu_{\max }$ from the same source used for the trade-offs in part A.

improve growth at high substrate levels (Figure 1B). To model this trade-off, information about the evolutionary potential of cells with regard to $\mu_{\max }$ and $k_{S}$ are required, which are difficult to come by. We have collected some data for E. coli ${ }^{15}$ and $S$. cerevisiae ${ }^{16}$. A different approach is to use a mechanistic computational model, optimize it under different external substrate concentrations, and then derive the $\mu_{\max }$ and $k_{S}$. We included this method for these same species, and for E. coli we included anaerobic conditions ${ }^{17,18}$. Note that in some cases the trade-off is related to transport kinetics ${ }^{16}$, but mostly it is a property of the whole cell and surfaces even with a single type of transporter. The resulting trade-offs are shown in figure 2 . To conveniently show the specialization of a strain to either low or high substrate as a one-dimensional trait, we introduce a normalized substrate specialization parameter $u$, where low $u$ corresponds to specialization on low substrate (e.g. protein investment in substrate transport) and high $u$ to specialization on high substrate (e.g. protein investment in ribosomes). See Appendix A.3 for details on the fitting of the trade-off curves.

There is no direct selection on the yield, but the yield affects the dynamics of substrate depletion, and therefore the environment for other species. There is quite some literature on trade-offs between $\mu_{\max }$ and $Y_{X / S}$ (see Beardmore et al. ${ }^{19}$ for a summary), but here we used yields from the same sources as the other growth parameters as much as possible. See Figure 2C for the implemented yields.

\subsection{Ecological coexistence and evolutionarily stable strategies}

We next investigate coexistence of well-adapted strains, where one strain is more adapted to low nutrients, while the other is more adapted to high nutrients. For this coexistence to be stable, the strains need to have a negative frequency dependent fitness (i.e. their fitness is lower the more abundant they are). There is indeed a negative frequency dependent effect, because the more abundant a high-substrate specialist is, the faster the substrate is depleted when it is high, and therefore the shorter the period of high substrate (Figure 1B). When both strains can invade a mono-culture of the other strain, no strain can outcompete the other and they will coexist. Therefore, we can find coexistence by studying mutual invasability.

To study the invasion of new types, and to find types that cannot be invaded, we use pairwise invasibility plots (PIPs) of adaptive dynamics. To construct these, we have to define the types by a one-dimensional parameter. Since types that are not on the trade-off line of $\mu_{\max }$ and $k_{S}$ can always be invaded by a type with the same $\mu_{\max }$ and a lower $k_{S}$, or the same $k_{S}$ and a higher $\mu_{\max }$, we can assume all types are on the trade-off line. We defined a new property, $u$, which specifies specialization on low to high resource levels on a scale of 0 to 1 , and assigns a $\mu_{\max }$ and $k_{S}$ to every value of $u$. The yields also change with $u$ (see Figure $2 \mathrm{~B}$ and Appendix Section A.3).

When we construct this PIP for E. coli under conditions commonly used for repeated transfer experiment, we observe that there is a single evolutionary stable strategy (see Figure 3A). If the resident would be very adapted to low substrate (low $u$ ), higher substrate specialists can invade, and if the resident is adapted to higher substrate (high $u$ ), lower substrate specialists can invade. In the ESS, no other type can invade (see inset in $3 \mathrm{~A}$ ). We can overlay this PIP with the PIP reflected in the main diagonal, to see when two types can mutually invade (green area in 3B).

Figure 3 depicts the results for one species, with one approximated trade-off and under one condition. Since we have an analytical expression for the selection coefficient, we can investigate many scenarios. However, for all trade-offs, from experimental and computational data, the general picture is similar (see Appendix Section A.5): There is a small area of ecological co-existence, but this coexistence is not evolutionary stable and the only attracting point is a single-type ESS. This means that two strains adapted to different conditions, such as a high-nutrient and low-nutrient condition, could coexist when placed together in a fluctuating environment. 
bioRxiv preprint doi: https://doi.org/10.1101/2021.05.18.444718; this version posted September 2, 2021. The copyright holder for this preprint (which was not certified by peer review) is the author/funder, who has granted bioRxiv a license to display the preprint in perpetuity. It is made available under aCC-BY 4.0 International license.

\section{A}

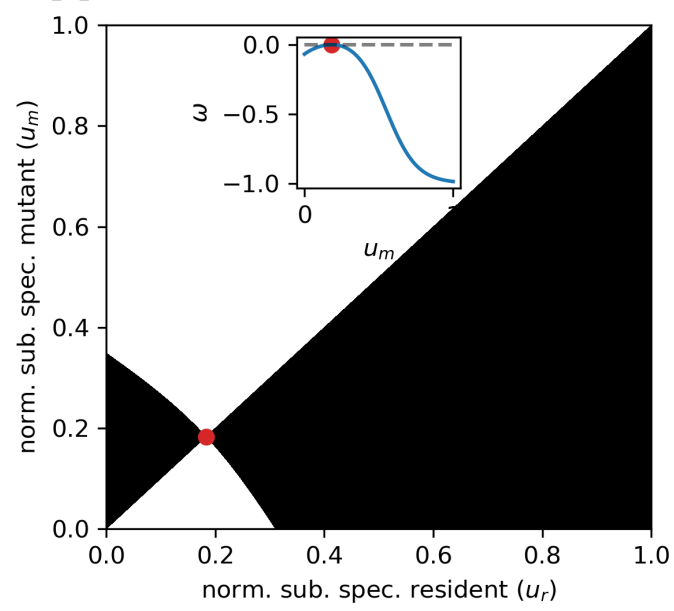

B

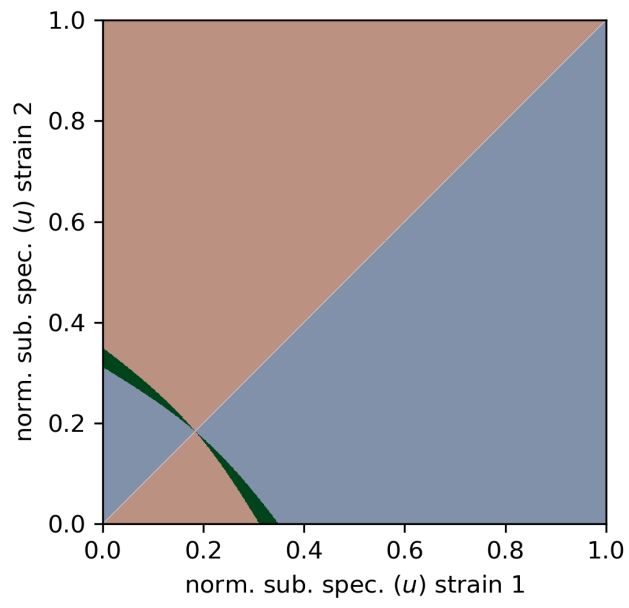

Figure 3: Invasion potential of different strategies. A Pairwise invasibility plot for the experimentally derived trade-off for $E$. coli at the conditions of the LTEE (initial glucose $=0.1375 \mathrm{mM}$, initial cells are $0.5 \cdot 10^{6}$ cells $\left./ \mathrm{ml}\right)^{9}$. The inset shows that the equilibrium is invasion stable. The equilibrium is also attracting and therefore an evolutionarily stable strategy (ESS). B Mutual invasibility plot. By reflecting the PIP of $\mathbf{A}$ over the main diagonal and overlaying it with the PIP, we can determine the area of mutual invasibility and therefore ecological coexistence. ${ }^{14}$

However, when they adapt in the same fluctuating regime, they will evolve in such a way that one of the strains will be lost, and a single strain will remain.

\subsection{Evolutionary coexistence in multiple species consortia}

In the previous section we showed that there are cases in which there are two types that will coexist over continued fluctuations. However, we mostly expect to observe coexisting types if the coexistence is not destabilized by evolution. We have not found this for a single species, but were we limited to only two well-studied species, a single substrate and few approximations of the trade-offs. It is possible that evolutionary coexistence could be found for different species. Now we investigate whether we can use a similar approach to investigate if evolutionary stable coexistence is possible in species consortia.

To investigate coexistence of multiple species with the above methods, we have to be able to represent multiple species in a one-dimensional trait space. Since in this case, a species with a higher affinity or higher maximal growth rate will out-compete the other, we can, for every value of the specialization trait $u$, which is directly linked to affinity, select the species with the highest growth rate. In that way we can use the methods for determining whether there is evolutionary stable coexistence on this artificially combined trade-off, and the results hold even if we allow the species to reach there full trait space. We combine two trade-offs in a single one, which is only possible when the trade-off curves intersect (see Figure 2). We will therefore model a co-culture of $E$. coli and $S$. cerevisiae under anaerobic conditions, and will use the computational trade-off for $E$. coli and the experimental trade-off for $S$. cerevisiae to illustrate this method. First we have to construct a new trade-off that combines the two (see Figure 4A and B and Appendix Section A.3.5). Of course one species cannot convert into another one by evolutionary change at the studied timescale, therefore we should discard mutations that cross the intersection of the trade-off curves. However, since this intersection is in a fitness minimum, such crossings is almost guaranteed not to happen, and no additional constraints have to be imposed.

When we construct the pairwise invasibility plot for the two-species trade-off, there are three equilibria, one local minimum at the species intersection and two local maxima, one for each species (Figure 4C). The single species maxima are both ESSes and will be reached when we start with a single species (Figure 5 and Appendix Figure A.8). With the same methods as before we can show there is an area of mutual invasibility between the species, shown as the green area in Figure 5. As can be seen, if both species would be adapted alone under these conditions, they would coexist when placed together. Moreover, using the analysis of trait evolution plots, we can show that there is an evolutionary attracting point in the species coexistence area ${ }^{14}$. With simulations (Appendix Figure A.8) we can find this point and we show numerically that in this point, the selection coefficient for all other types is negative (inset in Figure 5). This means that after the species coexist together, they will continue to evolve, but reach an evolutionary singular coalition (ESC).

\section{Discussion}

Nutrient fluctuations are abundant in nature, and are often mimicked in laboratory evolution studies with a serial transfer regime. In this paper we show that specialization on resource level in such fluctuating environments is not likely to lead to diversity within a species as a single or major cause, at the very least for the organisms investigated here, because while coexistence is possible, it will be destabilized by evolution. However, it could be a factor contributing to co-existence, such as in Turner et al. ${ }^{7}$, where this specialization is combined with 
A

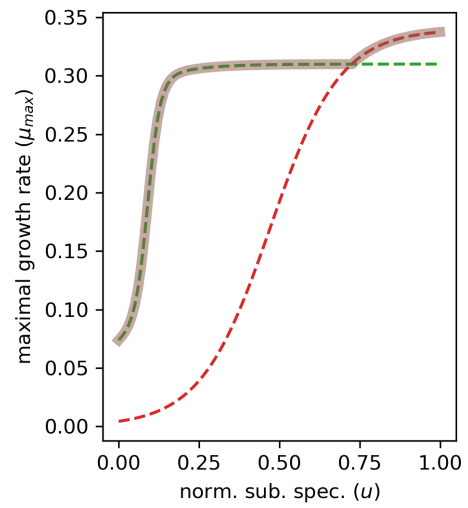

B

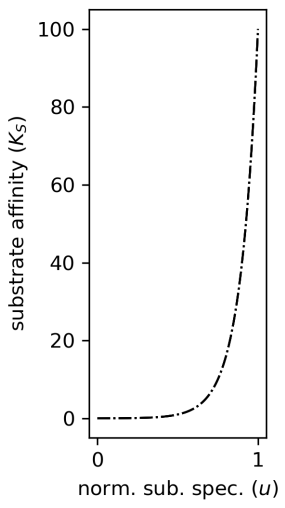

C

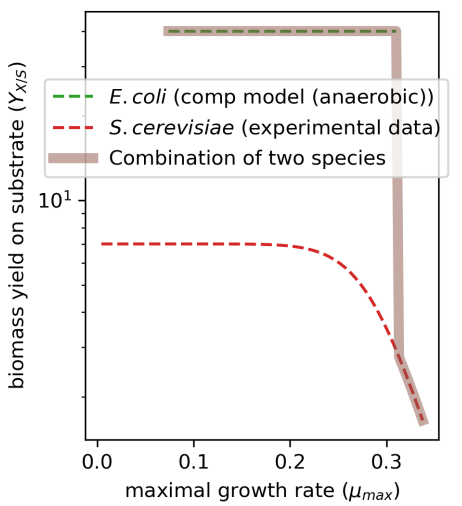

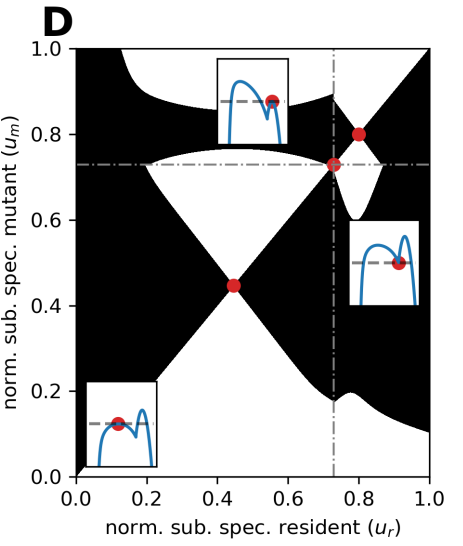

Figure 4: Combined trade-off of two species. A Dependency of the maximal growth rate $\left(\mu_{\max }\right)$ on the normalized specialization parameter $u$, which now signifies $k_{S}$ from 0.01 to 100 (B and Equation (A.6)). The maximum of the $\mu_{\max }$ of the two species is used for this combined trade-off (thick gray line). $\mathbf{C}$ The yield corresponding to the species from which the trade-off is takes is used for the yield of the combined trade-off. D In the PIP (with $x_{0}=10^{6}$ cells $\mathrm{ml}^{-1}$ and $s_{0}=500 \mathrm{mM}$ ) we can see there are three equilibria, of which the middle one is a local minimum corresponding to the switching point of one species to the other (gray dashes lines; those cannot be crossed by mutations). There are two equilibria that are attracting and locally invasion stable, which correspond to the ESS for each species.

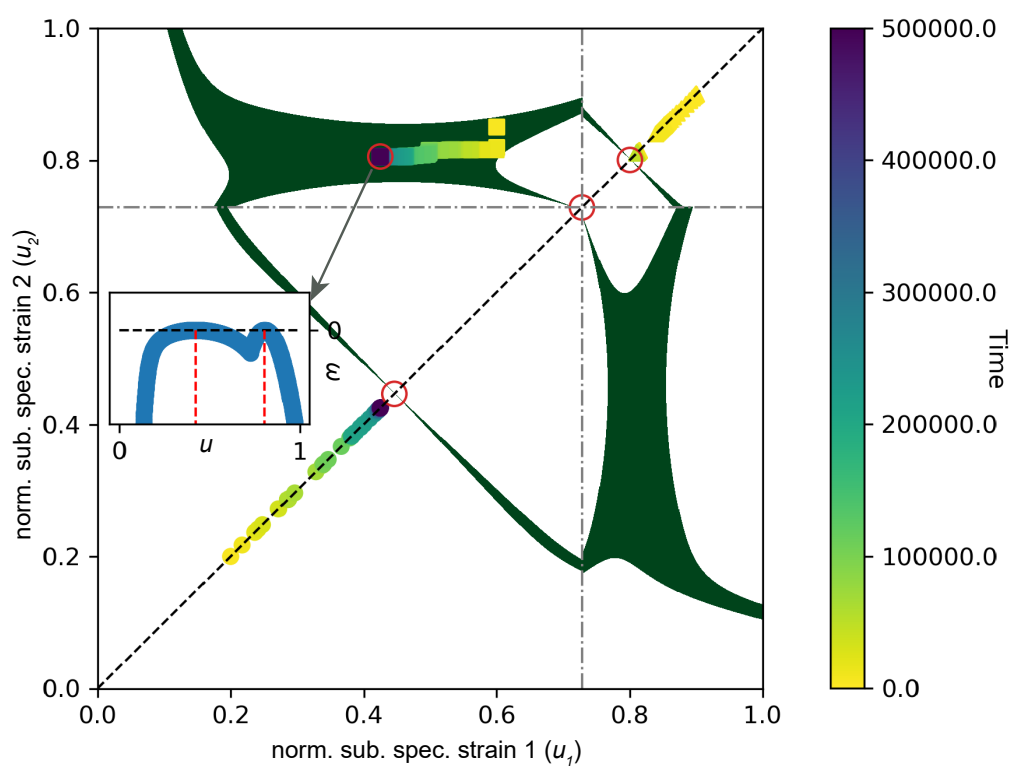

Figure 5: An evolutionarily singular coalition of two species. Three different simulations are plotted onto the area of coexistence, created with the mutual invasibility plot (see Appendix Figure A.8 for the simulations). When initially one species is present, a single species ESS is reached. However, when we start with two species within the area of coexistence, an evolutionarily singular coalition (ESC) is reached. As shown in the inset, when in this ESC all other types have a negative selection coefficient, and therefore this ESC is evolutionarily stable. 
cross-feeding. Our major result is that the same process can achieve evolutionarily stable coexistence between multiple species in a community. Since those species do not arise from a common ancestor, it is likely that these communities come together through invasion of one species in the environment of the other, and then adapt to each other, forming the evolutionarily stable coexistence.

Evolutionary coexistence between species is most likely when dilution is not too extreme, and relatively high cell densities remain before nutrients are replenished. This is because high dilution leads to a long growth phase, which benefits a fast growth strategy, making it difficult for low substrate specialists to survive (this was also found $i^{20}$ ). Natural habitats such as the mammalian gut satisfy such conditions.

We have used a trade-off between maximal growth rate and substrate affinity to determine the possible trait space of the organisms. Data and detailed models that can infer these properties are not abundant, therefore we focussed on E. coli and S. cerevisiae. We have shown some support for this trade-off, however Velicer and Lenski $^{21}$ set out to measure this trade-off experimentally in E. coli and found more contra- than supporting evidence. However, as they also note, perhaps their experiment was not long enough to actually reach the trade-off, and general growth performance mutations on the supplied substrate were selected for. Moreover, E. coli might not be the organisms where this phenomenon is most important, because it tends to use active transport that usually already coincides with a high affinity. This trade-off might be more relevant for other micro-organisms, for $\mathrm{CO} 2$ uptake by cyanobacteria and green algae ${ }^{22}$ or plants (see supplementary information in $^{19}$ ). We cannot exclude that for other organisms, within-species diversity can be explained by this mechanism, although we do not deem it to be very likely.

In Figure 5 we see bi-stability in the evolutionary sense, i.e. the reached ESS depends on the initial traits of the species. However, the proposed model can, besides coexistence, also show ecological bi-stability, i.e. the final outcome depends on the initial ratio of the strains. Bistability was also observed in another study with a trade-off between maximal growth rate and lag phase ${ }^{12}$. The conditions for bi-stability of single-strain states include mutual non-invasibility, and can therefore be studied with equation 7 . Bi-stability is only possible if the strain specialized on high substrate has a low numerical yield, such that when that strain is abundant, nutrients remain high, favoring itself and supplying the necessary positive feedback. However, when we look at the measured parameters, bi-stability is not observed (there is no overlay of non-invasibility areas in figure A.7). Note that bi-stability is not possible when instead of the initial biomass, the dilution is kept constant, because then the yield does not affect the invasion fitness anymore (see Appendix Section A.2.1).

We have only discussed the co-existence of two strains or species. Previous studies have shown theoretically more than two species could coexist, albeit mostly though numerical simulations or only showing neutral coexistence $^{5,6,12}$. However, based on trade-offs implemented here, more than two strains stable coexisting is in reality likely not feasible. Still, if specialization on an intermediate level of resource is a side-effect, it can still help a new variant (temporally) gain some benefit. Besides communities coexisting solely on a single substrate composition, more likely it is just one effect that can play a role in maintaining community diversity, and it would be interesting if resource level specialisation plays a role in studies or more complex communities ${ }^{23,24}$

Several open question remain. First, we have only studied adaptation on the pareto front, i.e. with strategies optimal in the $\mu_{\max }-k_{S}$ domain. However, mutants are often not directly perfectly adapted. It would be interesting to study what that would mean for the reachability of the evolutionarily stable coexistence. This could be done with (agent based) simulation (e.g. Virtual Microbes ${ }^{25}$ ). Second, we have simplified the growth to a single Monod equation. Although the basic principles underlying the results will not be affected, simulation could indicate how more complicated growth models could affect the result, such as a Hill equation, the underlying models for the tradeoffs ${ }^{18,17}$ or a genome scale model with uptake kinetics. Third, we have modeled predictable transfers after complete substrate depletion. It would be interesting to study whether less regular fluctuations influence the results. If nutrients are not completely depleted, this will benefit the high substrate specialist, and therefore coexistence will be less likely, but the conditions for coexistence could be investigated. Fourth, in the coexistence, the high substrate specialist is often more abundant than the low substrate specialist. If there would be a relation between the equilibrium ratio for the different strategies and the location of the ESC, this could simplify finding the ESC, which is difficult because an analytical solution for the fitness with more than one resident cannot be found. However, we have not been able to find this relation. Fifth, even more promising would be if we can determine the existence of an evolutionarily stable coexistence from the shape of the trade-off curves. Perhaps the methods used in ${ }^{26}$ could be a start for finding such results. Last, it would be ideal to have experimental verification of these results. For that, first, models and theory can be used to identify an experimental system that would be suitable, i.e. where we expect evolutionarily stable coexistence under some (initial) conditions. Then, experiments can be designed to determine if only resource level specialization achieves coexistence, or if it is one of the contributors. As long as a suitable experimental system is lacking, virtual organisms could be a first test.

In conclusion, we have shown that we can use adaptive dynamics and trade-offs based on experimental data to show the biologically relevance of an observed and suggested mechanism behind diversity of microbial communities in fluctuating environments. As more quantitative data becomes available and more mechanistic models can be parameterized, we can investigate how common it is that species could coexist by specialization on resource level. Moreover, we supply the techniques to investigate evolutionary stable diversity within and between species, which could also originate from different mechanisms.

\section{Acknowledgements}

I would like to thank Han Peters for help with the mathematical derivations, Hans Metz for help with applying adaptive dynamics techniques, Guilhem Doulcier for the online availability of his lecture notes and code on 
bioRxiv preprint doi: https://doi.org/10.1101/2021.05.18.444718; this version posted September 2, 2021. The copyright holder for this preprint (which was not certified by peer review) is the author/funder, who has granted bioRxiv a license to display the preprint in perpetuity. It is made available under aCC-BY 4.0 International license.

adaptive dynamics and Juan Bonachela, Bob Planqué, Martijn Egas and Huub Hoefsloot for helpful discussions.

\section{References}

[1] Nandita R. Garud, Benjamin H. Good, Oskar Hallatschek, and Katherine S. Pollard. Evolutionary dynamics of bacteria in the gut microbiome within and across hosts. PLOS Biology, 17(1):e3000102, January 2019. ISSN 1545-7885. doi: 10.1371/journal.pbio.3000102. URL https://dx.plos.org/10.1371/journal.pbio.3000102.

[2] Shijie Zhao, Tami D. Lieberman, Mathilde Poyet, Kathryn M. Kauffman, Sean M. Gibbons, Mathieu Groussin, Ramnik J. Xavier, and Eric J. Alm. Adaptive Evolution within Gut Microbiomes of Healthy People. Cell Host ES Microbe, 25(5):656-667.e8, May 2019. ISSN 19313128. doi: 10.1016/j.chom.2019.03.007. URL https://linkinghub.elsevier.com/retrieve/pii/S1931312819301593.

[3] Benjamin H. Good, Michael J. McDonald, Jeffrey E. Barrick, Richard E. Lenski, and Michael M. Desai. The dynamics of molecular evolution over 60,000 generations. Nature, 551(7678):45-50, November 2017. ISSN 1476-4687. doi: 10.1038/nature24287. Number: 7678 Publisher: Nature Publishing Group.

[4] Bruce R. Levin. Coexistence of Two Asexual Strains on a Single Resource. Science, 175(4027): 1272-1274, March 1972. ISSN 0036-8075, 1095-9203. doi: 10.1126/science.175.4027.1272. URL https://science.sciencemag.org/content/175/4027/1272. Publisher: American Association for the Advancement of Science Section: Reports.

[5] Frank M. Stewart and Bruce R. Levin. Partitioning of Resources and the Outcome of Interspecific Competition: A Model and Some General Considerations. The American Naturalist, 1973. ISSN 0003-0147. doi: 10.1086/282825. URL https://www.journals.uchicago.edu/doi/abs/10.1086/282825. Publisher: University of Chicago Press.

[6] Hal L. Smith. Bacterial competition in serial transfer culture. Mathematical Biosciences, 229(2):149-159, February 2011. ISSN 0025-5564. doi: 10.1016/j.mbs.2010.12.001. URL https://www.sciencedirect.com/science/article/pii/S0025556410001811.

[7] Paul E. Turner, Valeria Souza, and Richard E. Lenski. Tests of ecological mechanisms promoting the stable coexistence of two bacterial genotypes. Ecology, 77(7): 2119-2129, 1996. ISSN 1939-9170. doi: https://doi.org/10.2307/2265706. URL https://esajournals.onlinelibrary.wiley.com/doi/abs/10.2307/2265706. _eprint: https://esajournals.onlinelibrary.wiley.com/doi/pdf/10.2307/2265706.

[8] Michael Manhart, Bharat V. Adkar, and Eugene I. Shakhnovich. Trade-offs between microbial growth phases lead to frequency-dependent and non-transitive selection. Proceedings of the Royal Society B: Biological Sciences, 285(1872):20172459, February 2018. doi: 10.1098/rspb.2017.2459. URL https://royalsocietypublishing.org/doi/10.1098/rspb.2017.2459. Publisher: Royal Society.

[9] Farida Vasi, Michael Travisano, and Richard E Lenski. Long-term experimental evolution in Escherichia coli. II. Changes in life-history traits during adaptation to a seasonal environment. The american naturalist, 144(3):432-456, 1994. Publisher: University of Chicago Press.

[10] Michael J Wiser, Noah Ribeck, and Richard E Lenski. Long-term dynamics of adaptation in asexual populations. Science, 342(6164):1364-1367, 2013. Publisher: American Association for the Advancement of Science.

[11] Luis-Miguel Chevin. On measuring selection in experimental evolution. $\quad B i$ ology Letters, 7(2):210-213, April 2011. doi: 10.1098/rsbl.2010.0580. URL https://royalsocietypublishing.org/doi/10.1098/rsbl.2010.0580. Publisher: Royal Society.

[12] Michael Manhart and Eugene I. Shakhnovich. Growth tradeoffs produce complex microbial communities on a single limiting resource. Nature Communications, 9(1):3214, August 2018. ISSN 2041-1723. doi: 10.1038/s41467-018-05703-6. URL https://www.nature.com/articles/s41467-018-05703-6. Number: 1 Publisher: Nature Publishing Group.

[13] Zhiyuan Li, Bo Liu, Sophia Hsin-Jung Li, Christopher G. King, Zemer Gitai, and Ned S. Wingreen. Modeling microbial metabolic trade-offs in a chemostat. PLOS Computational Biology, 16(8):e1008156, August 2020. ISSN 1553-7358. doi: 10.1371/journal.pcbi.1008156. URL https://journals.plos.org/ploscompbiol/article?id=10.1371/journal.pcbi.1008156. Publisher: Public Library of Science.

[14] S.A.H. Geritz, E. Kisdi, G. MeszeNA, and J.A.J. Metz. Evolutionarily singular strategies and the adaptive growth and branching of the evolutionary tree. Evolutionary Ecology, 12(1):35-57, January 1998. ISSN 1573-8477. doi: 10.1023/A:1006554906681. URL https://doi.org/10.1023/A:1006554906681.

[15] Kai W Wirtz. A generic model for changes in microbial kinetic coefficients. Journal of Biotechnology, 97 (2):147-162, 2002. Publisher: Elsevier. 
bioRxiv preprint doi: https://doi.org/10.1101/2021.05.18.444718; this version posted September 2, 2021. The copyright holder for this

preprint (which was not certified by peer review) is the author/funder, who has granted bioRxiv a license to display the preprint in perpetuity. It is made available under aCC-BY 4.0 International license.

[16] Karin Elbing, Christer Larsson, Roslyn M. Bill, Eva Albers, Jacky L. Snoep, Eckhard Boles, Stefan Hohmann, and Lena Gustafsson. Role of Hexose Transport in Control of Glycolytic Flux in Saccharomyces cerevisiae. Applied and Environmental Microbiology, 70(9):5323-5330, September 2004. ISSN 0099-2240, 1098-5336. doi: 10.1128/AEM.70.9.5323-5330.2004. Publisher: American Society for Microbiology Section: PHYSIOLOGY AND BIOTECHNOLOGY.

[17] Meike T. Wortel, Elad Noor, Michael Ferris, Frank J. Bruggeman, and Wolfram Liebermeister. Metabolic enzyme cost explains variable trade-offs between microbial growth rate and yield. PLOS Computational Biology, 14(2):e1006010, February 2018. ISSN 1553-7358. doi: 10.1371/journal.pcbi.1006010. Publisher: Public Library of Science.

[18] Meike T. Wortel, Evert Bosdriesz, Bas Teusink, and Frank J. Bruggeman. Evolutionary pressures on microbial metabolic strategies in the chemostat. Scientific Reports, 6(1):29503, July 2016. ISSN 2045-2322. doi: 10.1038/srep29503. Number: 1 Publisher: Nature Publishing Group.

[19] Robert E. Beardmore, Ivana Gudelj, David A. Lipson, and Laurence D. Hurst. Metabolic trade-offs and the maintenance of the fittest and the flattest. Nature, 472(7343):342-346, April 2011. ISSN 0028-0836, 1476-4687. doi: 10.1038/nature09905.

[20] Clare I. Abreu, Jonathan Friedman, Vilhelm L. Andersen Woltz, and Jeff Gore. Mortality causes universal changes in microbial community composition. Nature Communications, 10(1):2120, May 2019. ISSN 20411723. doi: 10.1038/s41467-019-09925-0. URL https://www.nature.com/articles/s41467-019-09925-0. Number: 1 Publisher: Nature Publishing Group.

[21] Gregory J. Velicer and Richard E. Lenski. Evolutionary Trade-Offs Under Conditions of Resource Abundance and Scarcity: Experiments with Bacteria. Ecology, 80(4):1168-1179, 1999. ISSN 1939-9170. doi: https://doi.org/10.1890/0012-9658(1999)080[1168:ETOUCO]2.0.CO;2.

[22] Xing Ji, Jolanda M H Verspagen, Maayke Stomp, and Jef Huisman. Competition between cyanobacteria and green algae at low versus elevated CO2: who will win, and why? Journal of Experimental Botany, 68(14):3815-3828, September 2017. ISSN 0022-0957. doi: 10.1093/jxb/erx027. URL https://doi.org/10.1093/jxb/erx027.

[23] Joshua E. Goldford, Nanxi Lu, Djordje Baji, Sylvie Estrela, Mikhail Tikhonov, Alicia Sanchez-Gorostiaga, Daniel Segr, Pankaj Mehta, and Alvaro Sanchez. Emergent simplicity in microbial community assembly. Science, 361(6401):469-474, August 2018. ISSN 0036-8075, 1095-9203. doi: 10.1126/science.aat1168. URL https://science.sciencemag.org/content/361/6401/469.

[24] Amir Erez, Jaime G Lopez, Benjamin G Weiner, Yigal Meir, and Ned S Wingreen. Nutrient levels and trade-offs control diversity in a serial dilution ecosystem. eLife, 9:e57790, September 2020. ISSN 2050084X. doi: 10.7554/eLife.57790. URL https://doi.org/10.7554/eLife.57790. Publisher: eLife Sciences Publications, Ltd.

[25] Bram van Dijk, Jeroen Meijer, Thomas D. Cuypers, and Paulien Hogeweg. Trusting the hand that feeds: microbes evolve to anticipate a serial transfer protocol as individuals or collectives. BMC Evolutionary Biology, 19(1):201, November 2019. ISSN 1471-2148. doi: 10.1186/s12862-019-1512-2. URL https://doi.org/10.1186/s12862-019-1512-2.

[26] Elias Ehrlich, Lutz Becks, and Ursula Gaedke. Trait-fitness relationships determine how trade-off shapes affect species coexistence. Ecology, 98(12):3188-3198, December 2017. ISSN 00129658. doi: 10.1002/ecy.2047.

[27] Meike T. Wortel, Han Peters, Josephus Hulshof, Bas Teusink, and Frank J. Bruggeman. Metabolic states with maximal specific rate carry flux through an elementary flux mode. The FEBS Journal, 281(6):1547-1555, 2014. ISSN 1742-4658. doi: https://doi.org/10.1111/febs.12722. URL https://febs.onlinelibrary.wiley.com/doi/abs/10.1111/febs.12722. _eprint: https://febs.onlinelibrary.wiley.com/doi/pdf/10.1111/febs.12722.

[28] Johan H. van Heerden, Meike T. Wortel, Frank J. Bruggeman, Joseph J. Heijnen, Yves J. M. Bollen, Robert Planqu, Josephus Hulshof, Tom G. O'Toole, S. Aljoscha Wahl, and Bas Teusink. Lost in transition: startup of glycolysis yields subpopulations of nongrowing cells. Science (New York, N.Y.), 343(6174):1245114, February 2014. ISSN 1095-9203. doi: 10.1126/science.1245114.

[29] Heinrich Senn, Urs Lendenmann, Mario Snozzi, Geoffrey Hamer, and Thomas Egli. The growth of Escherichia coli in glucose-limited chemostat cultures: a re-examination of the kinetics. Biochimica et Biophysica Acta (BBA)-General Subjects, 1201(3):424-436, 1994. Publisher: Elsevier. 


\section{A Appendix}

\section{A.1 Parameters and variables}

\begin{tabular}{lll} 
Symbol & Name & Units \\
\hline$x$ & Biomass & $10^{6} \mathrm{cells}^{-1}$ \\
$s$ & Substrate & $\mathrm{mM}$ \\
$\mu$ or $\mu_{\max }$ & Maximal growth rate & $\mathrm{h}^{-1}$ \\
$k$ or $k_{S}$ & Monod constant (substrate at half maximal growth) & $\mathrm{mM}$ \\
$y$ or $Y_{X / S}$ & Yield of biomass on substrate & $10^{9}{\text { cells } \mathrm{mmol}^{-1}}^{-1}$
\end{tabular}

\section{A.2 Derivation of the mutant fitness and the selection gradients}

To find a fitness of a mutant $\left(x^{*}\right)$, we need to calculate how it increases in frequency when it invades in the population of a resident $(x)$. We will assume that this mutant is in such a small amount that the mutant does not affect the metabolite profile $s(t)$. Then, we will deduce the growth factor $\left(\frac{x^{*}(\infty)}{x^{*}(0)}\right)$ for the mutant. For the derivations we will use the notation of (2).

$$
\begin{aligned}
\frac{d x^{*}}{d t} & =\mu^{*} \frac{s}{k^{*}+s} x^{*} \\
\frac{1}{x^{*}} \frac{d x^{*}}{d t} & =\mu^{*} \frac{s}{k^{*}+s} \\
\frac{d}{d t}\left(\ln x^{*}\right) & =\mu^{*} \frac{s}{k^{*}+s}
\end{aligned}
$$

Note that the right hand side depends on $t$ but not on $x^{*}$, because we assumed that the metabolite profile is determined by the resident. Thus:

$$
\begin{aligned}
\ln \left(x^{*}(\infty)\right)-\ln \left(x^{*}(0)\right) & =\int_{0}^{\infty} \mu^{*} \frac{s}{k^{*}+s} d t \\
\frac{x^{*}(\infty)}{x_{0}^{*}} & =e^{\int_{0}^{\infty} \mu^{*} \frac{s}{k^{*}+s} d t}
\end{aligned}
$$

To calculate the above integral we change variables from $s(t)$ to $s$. Because we know that $s$ runs from $s_{0}$ to 0 , we integrate from $s$ from $s_{0}$ to 0 in stead of $t$ from 0 to $\infty$. We do have to multiply with the derivative $\frac{d t}{d s}$ :

$$
\int_{0}^{\infty} \mu^{*} \frac{s(t)}{k^{*}+s(t)} d t=\int_{s_{0}}^{0} \mu^{*} \frac{s}{k^{*}+s} \frac{d t}{d s} d s
$$

We can calculate $\frac{d t}{d s}$ from equations (2). First we express $x$ in $s$ and constants:

$$
\begin{aligned}
x(t)-x(0) & =y(s(0)-s(t)) \\
x(t) & =y\left(s_{0}-s(t)\right)+x_{0}
\end{aligned}
$$

Then we can work out $\frac{d s}{d t}$ :

$$
\begin{aligned}
\frac{d s}{d t} & =-\frac{1}{y} \mu \frac{s}{k+s} x \\
& =-\frac{1}{y} \mu \frac{s}{k+s}\left(y\left(s_{0}-s\right)+x_{0}\right) \\
& =-\mu \frac{s\left(\frac{x_{0}}{y}+s_{0}-s\right)}{k+s}
\end{aligned}
$$

Then we get:

$$
\frac{d t}{d s}=-\frac{1}{\mu} \frac{k+s}{s\left(\frac{x_{0}}{y}+s_{0}-s\right)}
$$

Now we can use equation (14) to calculate the integral (11):

$$
\begin{aligned}
\int_{s_{0}}^{0} \mu^{*} \frac{s}{k^{*}+s} \frac{d t}{d s} d s & =\frac{\mu^{*}}{\mu} \int_{0}^{s_{0}} \frac{k+s}{k^{*}+s} \frac{1}{\frac{x_{0}}{y}+s_{0}-s} d s \\
& =\frac{\mu^{*}}{\mu}\left[\frac{k-k^{*}}{k^{*}+\frac{x_{0}}{y}+s_{0}} \ln \left(k^{*}+s\right)-\frac{k+\frac{s_{0}}{y}+s_{0}}{k^{*}+\frac{s_{0}}{y}+s_{0}} \ln \left(\frac{x_{0}}{y}+s_{0}-s\right)\right]_{s=0}^{s=s_{0}} \\
& =\frac{\mu^{*}}{\mu}\left(\frac{k-k^{*}}{k^{*}+\frac{x_{0}}{y}+s_{0}} \ln \left(\frac{k^{*}+s_{0}}{k^{*}}\right)+\frac{k+\frac{x_{0}}{y}+s_{0}}{k^{*}+\frac{x_{0}}{y}+s_{0}} \ln \left(\frac{x_{0}+y s_{0}}{x_{0}}\right)\right)
\end{aligned}
$$

To calculate the growth factor of the mutant $\left(\frac{x^{*}(\infty)}{x^{*}(0)}\right)$, we have to take $e$ to the power the above integral (see equation (10)):

$$
\frac{x^{*}(\infty)}{x_{0}^{*}}=\left(\frac{k^{*}+s_{0}}{k^{*}}\right)^{\frac{\mu^{*}}{\mu} \frac{k-k^{*}}{k^{*}+\frac{x_{0}}{y}+s_{0}}}\left(\frac{x_{0}+y s_{0}}{x_{0}}\right)^{\frac{\mu^{*}}{\mu} \frac{k+\frac{x_{0}}{y}+s_{0}}{k^{*}+\frac{x_{0}}{y}+s_{0}}}
$$


Using the definition (5), we can describe the fitness as:

$$
\frac{\ln \left(x_{\infty}^{*} / x_{0}^{*}\right)}{\ln \left(x_{\infty} / x_{0}\right)}=\frac{\ln \left[\left(\frac{k^{*}+s_{0}}{k^{*}}\right)^{\frac{\mu^{*}}{\mu} \frac{k-k^{*}}{k^{*}+\frac{x_{0}}{y}+s_{0}}}\left(\frac{x_{0}+y s_{0}}{x_{0}}\right)^{\frac{\mu^{*}}{\mu} \frac{k+\frac{x_{0}}{y}+s_{0}}{k^{*}+\frac{x_{0}}{y}+s_{0}}}\right]}{\ln \left[\frac{x_{0}+y s_{0}}{x_{0}}\right]}
$$

\section{A.2.1 Constant dilution $(d)$ instead of constant initial biomass $\left(x_{0}\right)$}

Here we do not start every transfer with a fixed biomass concentration, but instead fix the dilution from one transfer to the next. This means that the biomass at the beginning is equal to the final biomass divided by the dilution factor $d$ :

The fitness then becomes:

$$
\begin{aligned}
& x_{0}=\frac{x_{\infty}}{d}=\frac{x_{0}+y s_{0}}{d} \\
& x_{0}=\frac{y s_{0}}{d-1}
\end{aligned}
$$

$$
\frac{\ln \left(x_{\infty}^{*} / x_{0}^{*}\right)}{\ln \left(x_{\infty} / x_{0}\right)}=\frac{\ln \left[\left(\frac{k^{*}+s_{0}}{k^{*}}\right)^{\frac{\mu^{*}}{\mu} \frac{k-k^{*}}{k^{*}+\frac{d}{d-1} s_{0}}} d^{\frac{\mu^{*}}{\mu} \frac{k+\frac{d}{d-1} s_{0}}{k^{*}+\frac{d}{d-1} s_{0}}}\right]}{\ln d}
$$

In this case the yield is removed from the equation, because $x_{0}$ will automatically be adjusted by the yield, and the nutrient profile will not depend on the yield anymore.

\section{A.3 Trade-offs between $\mu_{\max }, k_{S}$ and $y$}

For this trade-off to be effective, the species with a higher $\mu_{\max }$ needs to have a lower $\mu_{\max } / k_{S}$, because this is a minimum requirement for having a higher growth rate at low nutrient concentrations, as also mentioned in ${ }^{7}$. Those curves are depicted in figure A.1.
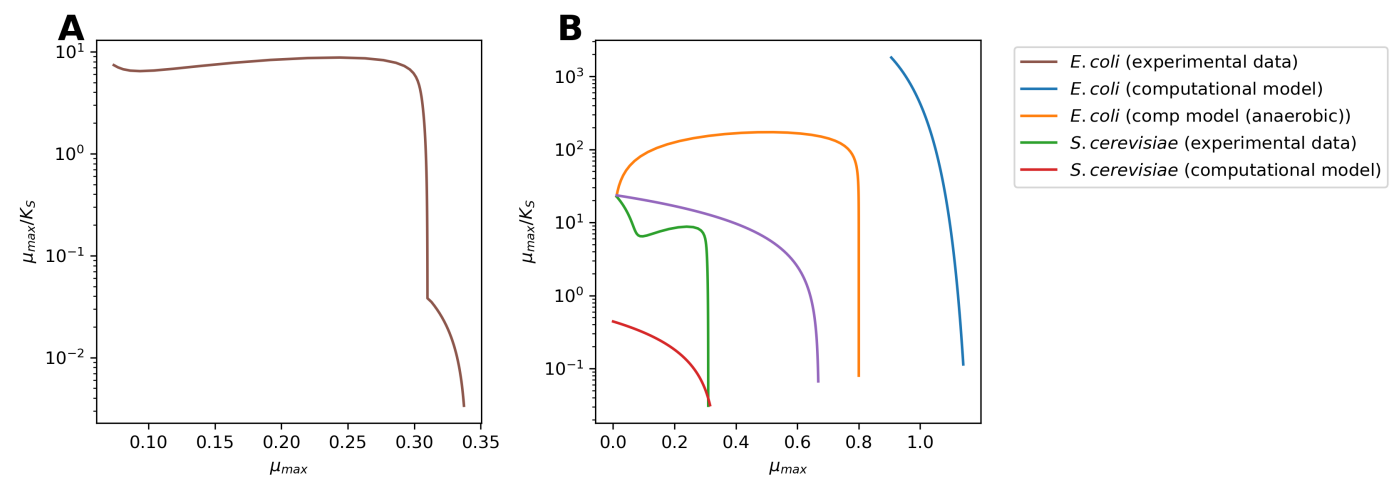

Figure A.1: Trade-offs between growth parameters. A Trade-off between $\mu_{\max }$ and $\mu_{\max } / k_{S}$ for the two-species case. B Trade-off between $\mu_{\max }$ and $\mu_{\max } / k_{S}$ for the individual curves. 


\section{A.3.1 E. coli from experimental data}

A trade-off between maximal growth rate and affinity has been fitted to experimental data ${ }^{15}$ :

$$
\mu_{\max }=\mu^{r e f} \frac{\log \left(\frac{k}{k^{r e f}}\right)}{\log \left(\frac{k}{k^{r e f}}\right)+1}
$$

There was a small issue with the parameters reported in the paper (personal communication) and we have converted the parameter $k^{r e f}$ from $\mu g L^{-1}$ to $m M$. This results in the parameters $\mu^{r e f}=1.23 h^{-1}$ and $k^{r e f}=$ $3.056 \cdot 10^{-5} \mathrm{mM}$. Since we have no information on the yield for this data, we used a constant yield derived from

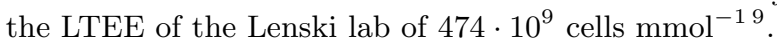

\section{A.3.2 E. coli from kinetic model of central metabolism}

For an actual evolutionary trade-off, we need to find the pareto optimum between different properties. Maximal growth rates and affinities in experimental conditions are usually for cells that are optimized for one of these properties. Another way to approach optimal conditions is by making a computational model of a species and then optimizing the model for different growth properties. We used a model of the central carbon metabolism of $E$. coli ${ }^{17}$ for this purpose. Optimal yield and growth under defined external conditions are achieved by elementary flux modes ${ }^{27}$, allowing us to find the pareto front by selecting the pareto optimal EFMs. Fitting a function through these pareto optimal EFMs for $\mu_{\max }$ and $k_{S}$, and another function for $Y_{X / S}$ and $\mu_{\max }$ leads to:

$$
\begin{aligned}
\mu_{\max } & =\mu^{r e f} \frac{\left(k^{r e f}\right)^{n}}{\frac{1}{k}^{n}+\left(k^{r e f}\right)^{n}} \\
Y_{X / S} & =y_{\max } \frac{\mu_{\max }}{\mu_{\max }+y_{\text {ref }}}
\end{aligned}
$$

With $\mu^{r e f}=0.8, k^{r e f}=417$ and $n=2.7$ for the first equation and $y_{\max }=495$ and $y_{\text {ref }}=0.0726$ for the second equation. For anaerobic growth we observe a different shape trade-off:

$$
\mu_{\max }=\mu_{1}^{r e f} \frac{k}{k+k_{1}^{r e f}}+\mu_{2}^{r e f} \frac{k^{n}}{k^{n}+\left(k_{2}^{r e f}\right)^{n}}
$$

With $\mu_{1}^{r e f}=0.1, k_{1}^{r e f}=3.9 \cdot 10^{-3}, \mu_{2}^{r e f}=0.21, k_{2}^{r e f}=2.3 \cdot 10^{-2}$ and $n=5.6$. Under anaerobic conditions

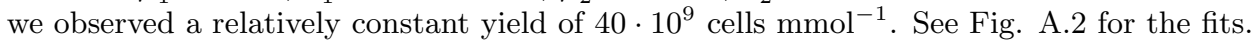



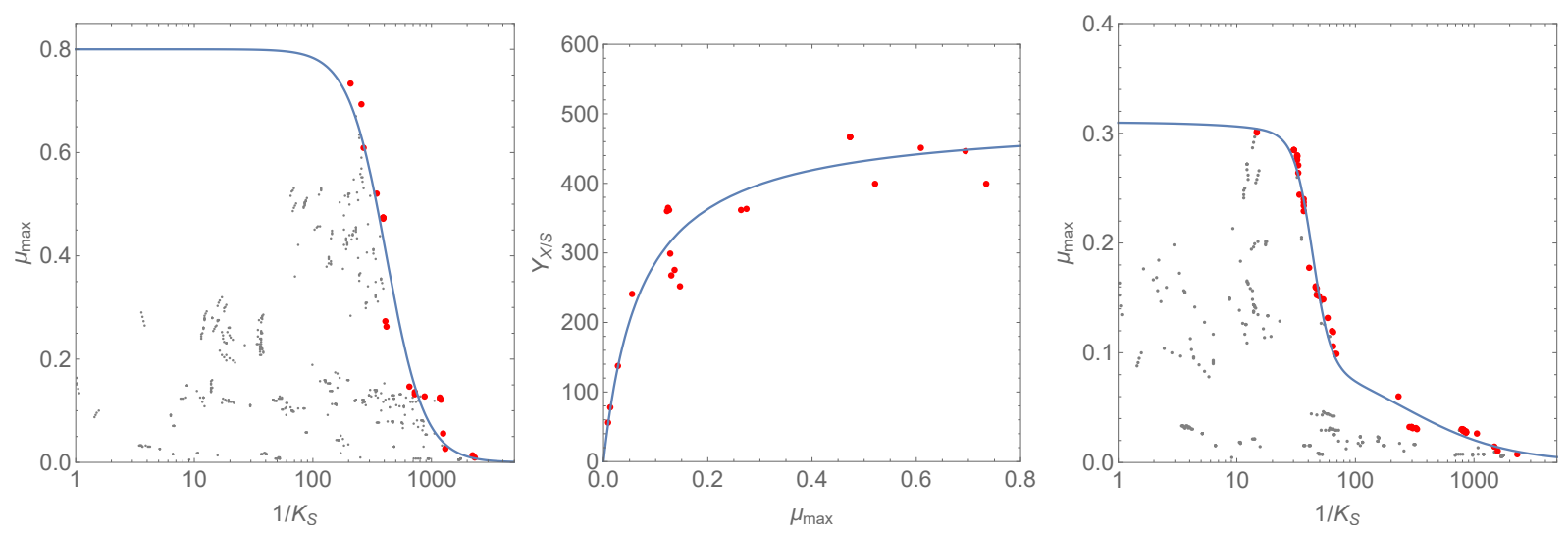

Figure A.2: Trade-off curves fitted to the pareto front for a computational model of $\boldsymbol{E}$. coli. A computational model is used to calculate $\mu_{\max }$ and $k_{S}$ of all Elementary Flux Modes (dots). The modes that form the pareto front (no other modes exist with both higher $\mu_{\max }$ and $k_{S}$ ) are colored red, and a function is fitted through those values (Eqs (21) and (22)). Left: The fit of the trade-off curve between $\mu_{\max }$ and $k_{S}$ under aerobic conditions. Middle: The fit of the trade-off curve between $\mu_{\max }$ and $Y_{X / S}$ under aerobic conditions. Right: The fit of the trade-off curve between $\mu_{\max }$ and $k_{S}$ under anaerobic conditions.

\section{A.3.3 S. cerevisiae from experimental data}

We used data from $S$. cerevisiae with all glucose transporters knocked out and single transporters or chimeras of two different transporters placed back ${ }^{16}$. The $K_{M}$ 's of the transporters as well as the growth rates are reported for these strains. We checked with a model of $S$. cerevisiae glycolysis ${ }^{28}$ and when the transporter $K_{M}$ is the only difference, this also reflects the substrate concentration of half maximal glycolysis rate. Assuming glycolysis rate is related to growth rate, in this case the $K_{M}$ of the transporter will be a good proxy for the $K_{S}$ of the cell. The function for these data is:

$$
\begin{aligned}
\mu_{\text {max }} & =\mu^{r e f} \frac{k_{S}}{k_{S}+k^{r e f}} \\
Y_{X / S} & =y_{\max } \frac{y_{r e f}^{m}}{\mu_{\text {max }}^{m}+y_{r e f}^{m}}
\end{aligned}
$$

With $\mu^{r e f}=0.34, k_{S}=0.77, y_{\max }=7, y_{\text {ref }}=0.3$ and $m=10$. The fits are depicted in Figure A.3.
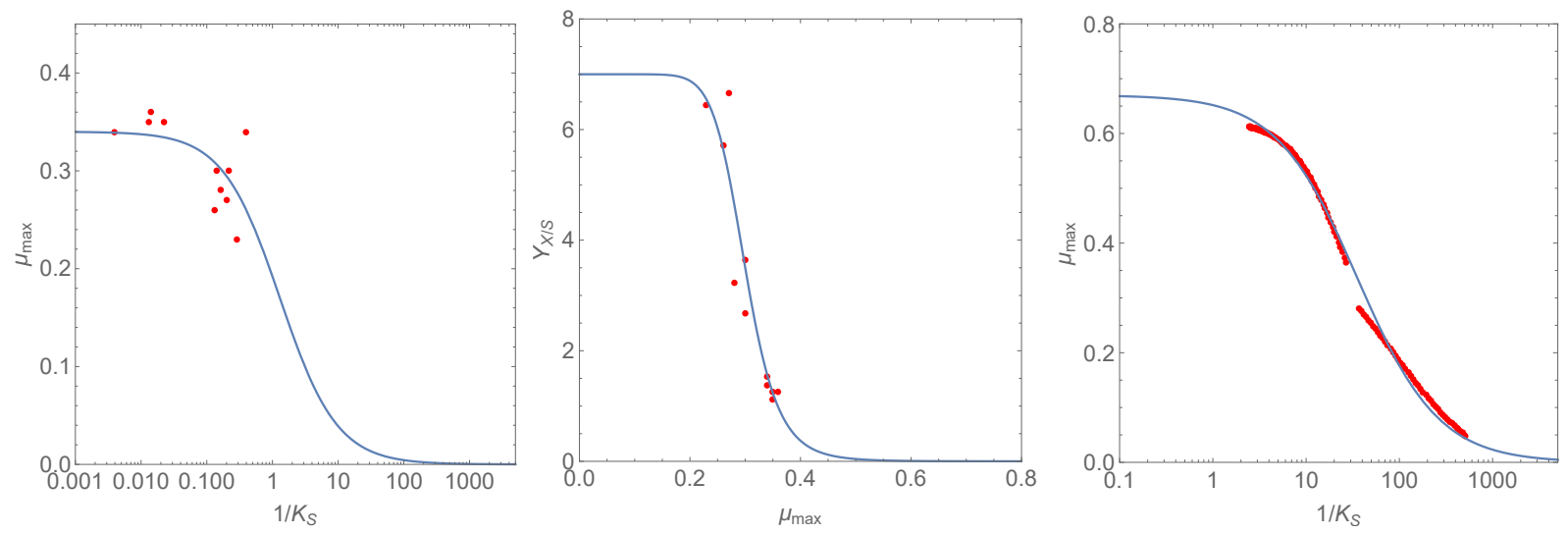

Figure A.3: Trade-off curves fitted to experimental data and a computational model of S. cerevisiae. Data from chimeric transporters is used to generate strains with different properties ${ }^{16}$ (dots). Left: A curve is fit for the $\mu_{\text {max }}-k_{S}$ trade-off (eq (23)). Middle: A curve is fit for the $\mu_{\max }-Y_{X / S}$ tradeoff (eq (23)). Right: A curve is fit to a self-replicator model parameterized on $S$. cerevisiae ${ }^{18}$ (eq (24)). 
bioRxiv preprint doi: https://doi.org/10.1101/2021.05.18.444718; this version posted September 2, 2021. The copyright holder for this

preprint (which was not certified by peer review) is the author/funder, who has granted bioRxiv a license to display the preprint in perpetuity. It is made available under aCC-BY 4.0 International license.

\section{A.3.4 S. cerevisiae from self-replicator model}

We also investigated a computational approach to get a trade-off curve for $S$. cerevisiae. We used a self-replicator model that includes all reactions to replicate itself, although in a very simplified form, and is parameterized on experimental data ${ }^{18}$. When we optimize this self-replicator model on different levels of the resource (glucose), and then fit Monod curves through each of the optimized parameters, we obtain different values for $\mu_{\max }$ and $k_{S}$. We fitted a trade-off curve through the corresponding $\mu_{\max }$ and $k_{S}$ values:

$$
\mu_{\text {max }}=\mu^{r e f} \frac{k_{S}}{k_{S}+k^{r e f}}
$$

with $\mu^{r e f}=0.67$ and $k^{r e f}=0.028$. See Figure A.3 for the fit. In the computational results, S. cerevisiae either fully respires or fully ferments. The yield is constant for such a regime, and therefore the yield that is used is a step function:

$$
\begin{aligned}
& Y_{X / S}=7.8 \text { when } \mu_{\max }<0.3 \\
& Y_{X / S}=3.7 \text { when } \mu_{\max } \geq 0.3
\end{aligned}
$$

To convert the yield from gramDW mmol Glucose ${ }^{-1}$ to $10^{9}$ cells mmol Glucose ${ }^{-1}$ we used a value of $15 \cdot 10^{-12}$ gram per cell.

\section{A.3.5 Combined trade-off of two species}

To investigate evolutionary coexistence of two species while still applying the same analytical and graphical analyses as for the single species case, we can make a single trade-off curve that encompasses the two separate trade-off curves. Because mutations cannot change one species in another, we have to make sure there are no mutations across the species boundary, which is likely if we have the species boundary in a fitness minimum.

To apply this we have combined the experimentally derived trade-off for S. cerevisiae (section A.3.3) and the computationally derived trade-off for $E$. coli for anaerobic conditions (section A.3.2). We used equation (22) below $k_{S}=8.21$ and equation (23) above (see Figure 4 ).

\section{A.4 Selection gradient}

The selection gradient $S_{X}$ for a property $X$ is the proportional partial derivative of the invasion fitness to the property. The selection coefficient (eq (6)) for $\mu$ t is always equal to 1 , because eq (7) is proportional to $\mu^{*}$, the derivative $\partial W / \partial \mu^{*}$ is exactly $W / \mu^{*}$. Since we assume the mutant has not influence on the nutrient profile, the selection gradient for $y^{*}$ is 0 . For $k^{*}$ this selection gradient in the point $k=k^{*}$ is equal to (we are keeping everything but the $k$ constant, so $\mu^{*} / \mu=1$ ). This leads to the following selection gradients:

$$
\begin{aligned}
& S_{\mu}=\frac{\mu^{*}}{W^{*}} \frac{\partial W^{*}}{\partial \mu^{*}}\left(\mu^{*}=\mu\right)=1 \\
& S_{y}=\frac{y^{*}}{W^{*}} \frac{\partial W^{*}}{\partial y^{*}}\left(y^{*}=y\right)=0 \\
& S_{k}=\frac{k^{*}}{W^{*}} \frac{\partial W^{*}}{\partial k^{*}}\left(k^{*}=k\right)=\frac{-k\left(1+\frac{\ln \left(\frac{k+s_{0}}{k}\right)}{\ln \left(\frac{x_{0}+y s_{0}}{x_{0}}\right)}\right)}{k+\frac{x_{0}}{y}+s_{0}}
\end{aligned}
$$

Using this equation, we can calculate selection on the Monod constant in an experimental setting. For the Long Term Evolution Experiment (values from ${ }^{9}$ ) we find $S_{k}=-0.00657233$, which agrees with the -0.0066 mentioned in the paper, where they obtain this result with numerical calculations. As this selection gradient is very low (compared to $S_{\mu}=1$ ) - and indeed they do not observe any increase in the affinity over the course of evolution -, we wondered if we expect to see selection on the Monod constant for different strains for E. coli or under different conditions. Higher values for $k$ lead to a higher selection gradient, and the $k$ for some $E$. coli strains is a factor 100 higher than the value of $0.727 \mu \mathrm{g} / \mathrm{mL}$ reported for REL606 ${ }^{9}$. At those higher values we can see that the selection of the $k_{S}$ does become important, as well as under different experimental conditions (see Figure A.4). Selection on the $k_{S}$ might be more important for other substrates or other organisms, e.g. if uptake is not active but based on a diffusion gradient such as for the yeast Saccharomyces cerevisiae the $k_{S}$ is usually (much) higher.

The landscape of invasion fitness and the gradient of this landscape (the selection gradient) can be visualized (Fig. A.5). $S_{k}$ is always lower or equal to $S_{\mu}$, which has implications for a $k / \mu$ trade-off, namely that the trade-off is only relevant if a $1 \%$ effect on the maximal growth rate has a bigger than $1 \%$ effect on the $k_{s}$.

When we plot the selection coefficient and the trade-off function for a resident in the LTEE of the Lenski $\mathrm{lab}^{9}$ we expect the selection to be almost completely on increasing the maximum growth rate. However, when we would repeat the experiment with a 100 times lower starting glucose concentration, we would expect a much more pronounced selection on the affinity (Figure A.5). 
bioRxiv preprint doi: https://doi.org/10.1101/2021.05.18.444718; this version posted September 2, 2021. The copyright holder for this preprint (which was not certified by peer review) is the author/funder, who has granted bioRxiv a license to display the preprint in perpetuity. It is made available under aCC-BY 4.0 International license.

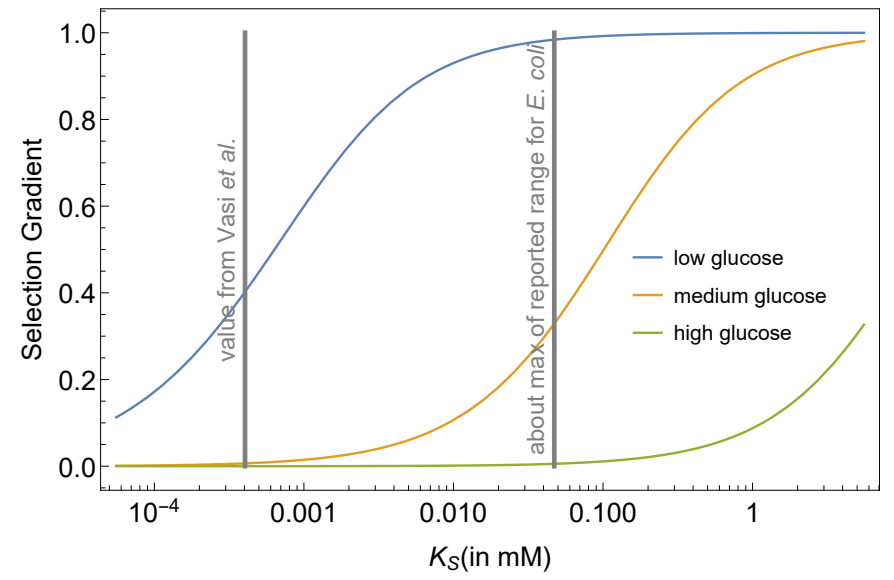

Figure A.4: Dependency of the selection gradient on the $k_{s}$. We have taken the selection gradient for a decrease in $k$ (minus the selection gradient). Range of $k_{S}$ values taken from ${ }^{29}$. Medium glucose is $25 \mu \mathrm{gmL}^{-1}=0.1375 \mathrm{mM}$ (values used in ${ }^{9}$ ), low glucose is 100 times lower, and high glucose 100 times higher.
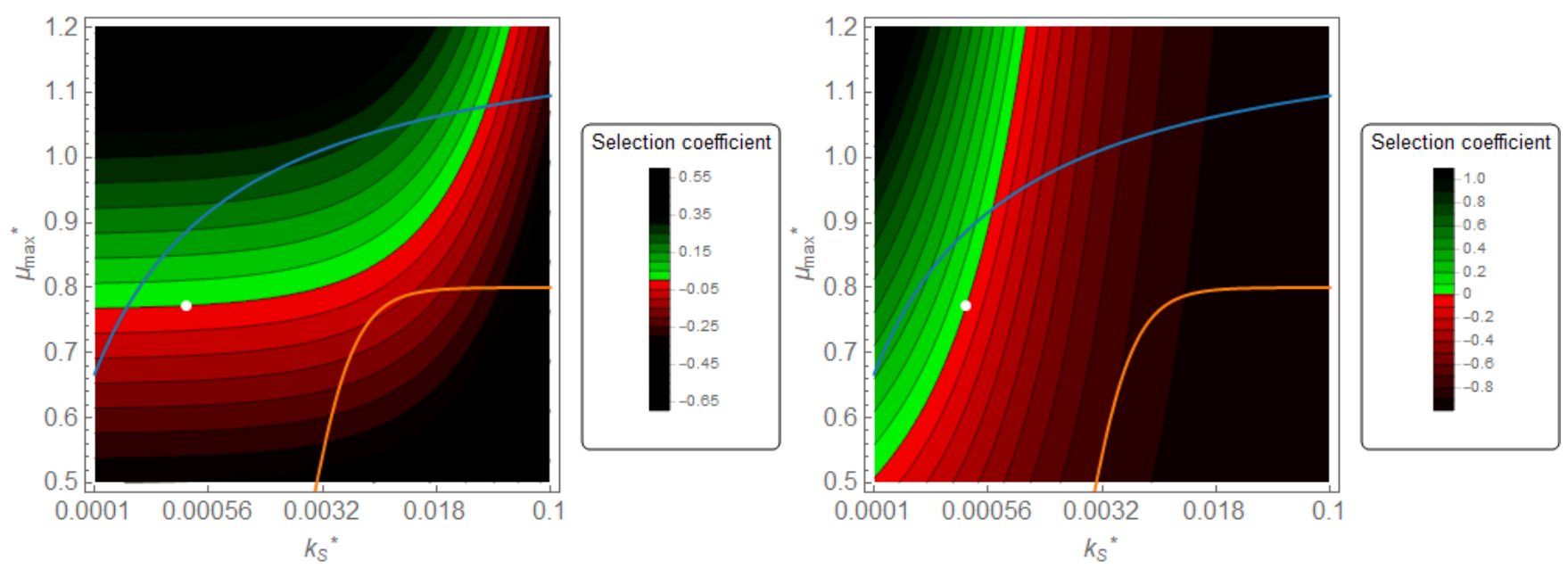

Figure A.5: Landscapes of selection coefficients for a given resident. The selection gradient is the slope in this landscape. Blue line is the trade-off from experimental data ${ }^{15}$ and orange line the trade-off from computational data $^{17}$. The resident is chosen from measurements ${ }^{9}$ (these are better than prediction from the computational trade-off). Left Conditions from the LTEE of the Lenski lab ${ }^{9}$. Selection mostly promotes maximum growth rate (higher selection coefficients for higher $\mu_{\max }$ within the trade-off curves, so mostly mutants with higher $\mu_{\max }$ can invade). Right 100 times lower glucose conditions. Now, selection is also on affinity, even strategies with lower $\mu_{\max }$ and higher $k_{S}$ can invade. 
bioRxiv preprint doi: https://doi.org/10.1101/2021.05.18.444718; this version posted September 2, 2021. The copyright holder for this preprint (which was not certified by peer review) is the author/funder, who has granted bioRxiv a license to display the preprint in perpetuity. It is made available under aCC-BY 4.0 International license.

\section{A.5 Invasive potential for different species, trade-offs and experimental con- ditions}

When we focus only on the trade-off line, we can simplify the figures from Figure A.5 to one dimension. We can use the second dimension to plot this not only for a single resident, but for all possible residents. For the different tradeoffs (Section A.3), we can plot the pairwise invasibility plots (Figure A.6) and by mirroring them over the diagonal and overlaying them, we can show the area of ecological coexistence (Figure A.7). 
bioRxiv preprint doi: https://doi.org/10.1101/2021.05.18.444718; this version posted September 2, 2021. The copyright holder for this preprint (which was not certified by peer review) is the author/funder, who has granted bioRxiv a license to display the preprint in perpetuity. It is made available under aCC-BY 4.0 International license.
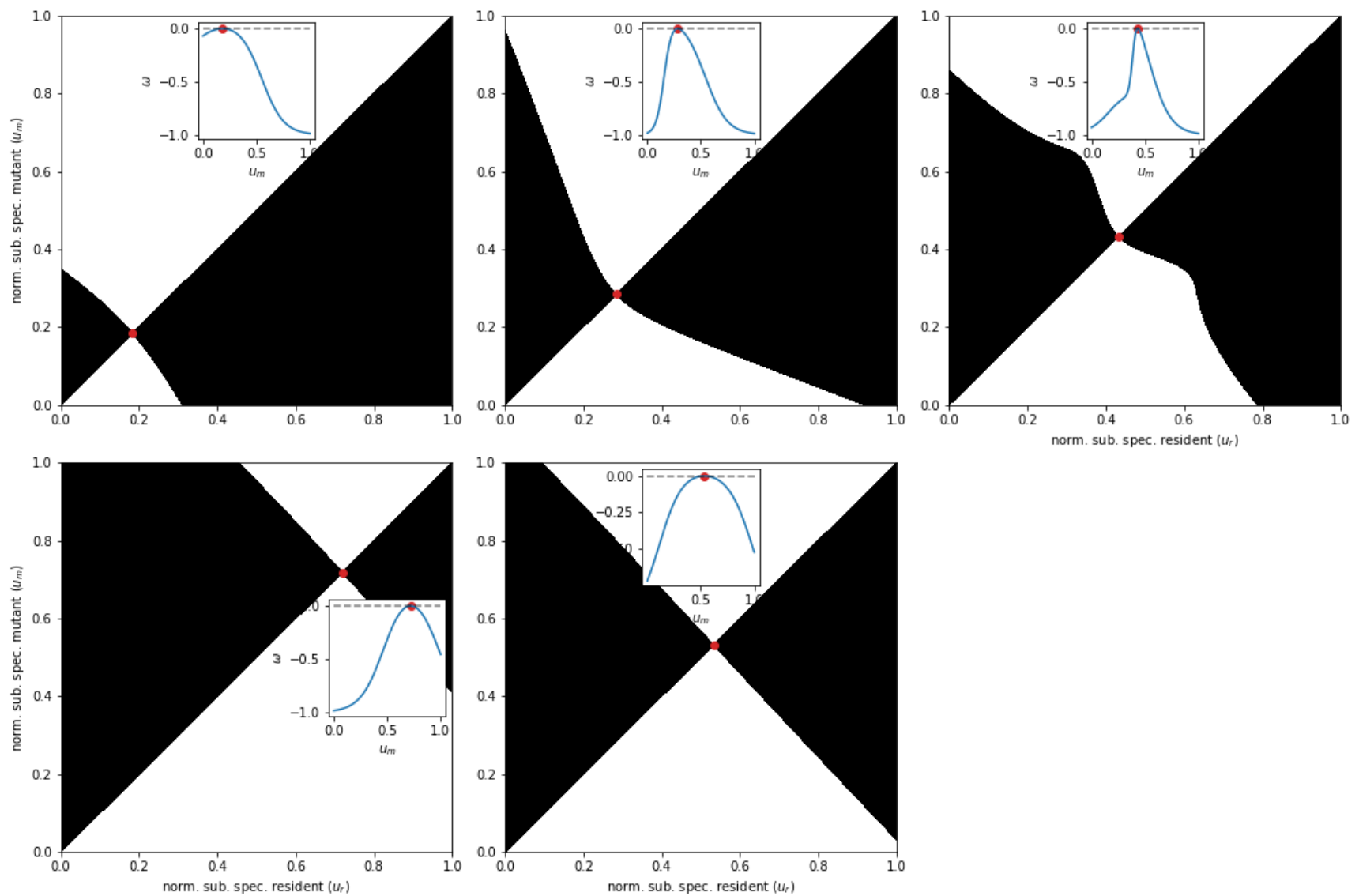

Figure A.6: Pairwise invasibility plots for the different trade-offs Top row: different trade-offs for E. coli (experimental fit, computational fit and computational fit anaerobic) with experimental conditions: initial glucose $=0.1375 \mathrm{mM}$ and initial cells are $0.5 \cdot 10^{6}$ cells $/ \mathrm{ml}$. For $E$. coli $k_{S}$ runs from 0.1 to 10 for $u$ from 0 to 1 (see Figure 2B and Eq (A.6)). Bottom row: different trade-offs for S. cerevisiae (experimental fit and computational fit) with experimental conditions: initial glucose $=100 \mathrm{mM}$ and initial cells are $0.1 \cdot 10^{6}$ cells $/ \mathrm{ml}$. For $S$. cerevisiae $k_{S}$ runs from 0.1 to 100 for $u$ from 0 to 1 (see Figure 4B and Eq (A.6)). 
bioRxiv preprint doi: https://doi.org/10.1101/2021.05.18.444718; this version posted September 2, 2021. The copyright holder for this preprint (which was not certified by peer review) is the author/funder, who has granted bioRxiv a license to display the preprint in perpetuity. It is made available under aCC-BY 4.0 International license.
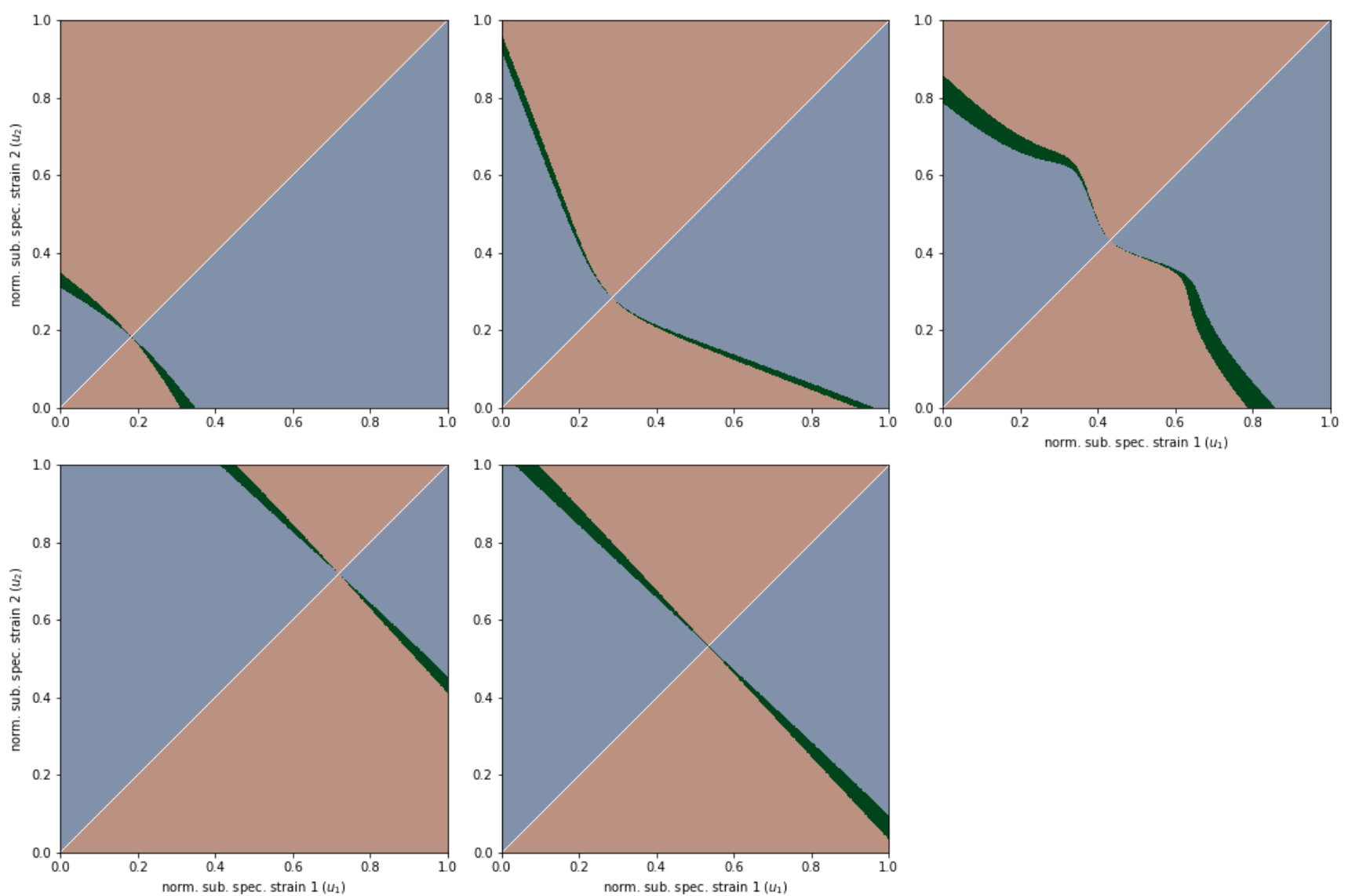

Figure A.7: Areas of coexistence for the different trade-offs Top row: different trade-offs for E. coli (experimental fit, computational fit and computational fit anaerobic) with experimental conditions: initial glucose $=0.1375 \mathrm{mM}$ and initial cells are $0.5 \cdot 10^{6}$ cells $/ \mathrm{ml}$. For $E$. coli $k_{S}$ runs from 0.1 to 10 for $u$ from 0 to 1 (see Figure 2B and Eq (A.6)). Bottom row: different trade-offs for S. cerevisiae (experimental fit and computational fit) with experimental conditions: initial glucose $=100 \mathrm{mM}$ and initial cells are $0.1 \cdot 10^{6}$ cells $/ \mathrm{ml}$. For $S$. cerevisiae $k_{S}$ runs from 0.1 to 100 for $u$ from 0 to 1 (see Figure 4B and Eq (A.6)). 


\section{A.6 Stochastic simulations}

When integrating the trade-off in our models we have chosen a 'specialization parameter' $u$, that runs from 0 (specialization on low resource) to 1 (specialization on high resource). The general conversion is:

$$
k=k_{\min } 10^{u \log _{10}\left(\frac{k_{\max }}{k_{\min }}\right)}
$$

We have used the two-species trade-off to determine $\mu_{\max }$ and $Y_{X / S}$ from $u$ (Section A.3.5 and Figure 4). For the simulations, we allowed for 51 different phenotypes at the same time, and tracked their fractions at the beginning and end of a fluctuation to determine the relative growth rate of a phenotype. All growing phenotypes could generate offspring with small but stochastic mutations, with a small chance, whenever free phenotypes were available (code adapted from online available code by Guilhem Doulcier). We simulated these systems until a stable phenotype distribution was reached (Figure A.8).

To plot the phenotype trajectories in Figure 5, we needed to convert the collection of phenotypes to one or two main trait values. We did this by taking only the phenotypes which had a density of more than $1 / 1000$ th of the most abundant phenotype. Then we checked if all those phenotypes were close together or far apart, and created either one or two groups. For every group we took the weighted mean to determine the consensus phenotype. See Figure A.9 for two examples of the outcome of this algorithm.

The evolutionary stable consortium was taken as the endpoint of the simulations starting from two phenotypes (A.8C), and then calculating the consensus phenotypes for that endpoint. To check if this consortium is indeed evolutionarily stable, we numerically calculated the invasion fitness of all possible strategies in the consortium (see inset in Figure 5). 
bioRxiv preprint doi: https://doi.org/10.1101/2021.05.18.444718; this version posted September 2, 2021. The copyright holder for this preprint (which was not certified by peer review) is the author/funder, who has granted bioRxiv a license to display the preprint in perpetuity. It is made available under aCC-BY 4.0 International license.

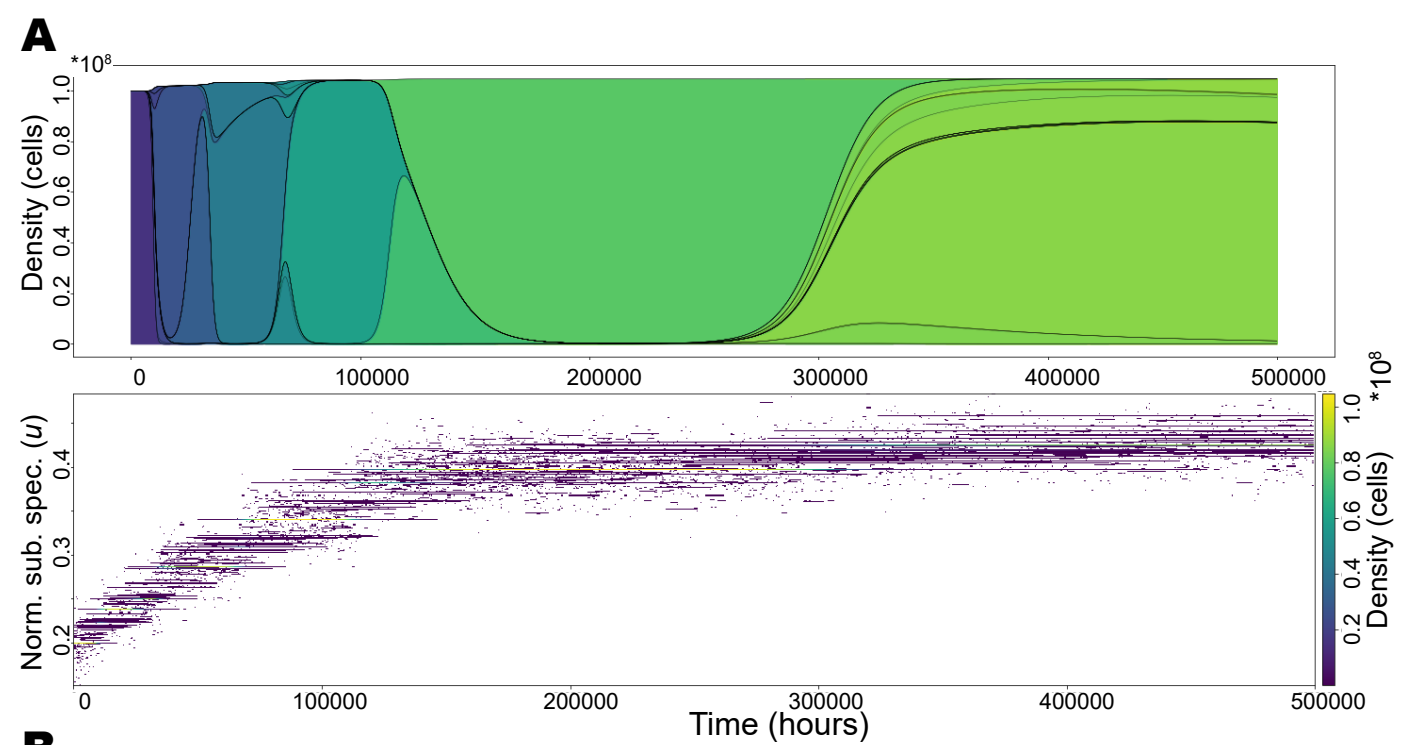

B
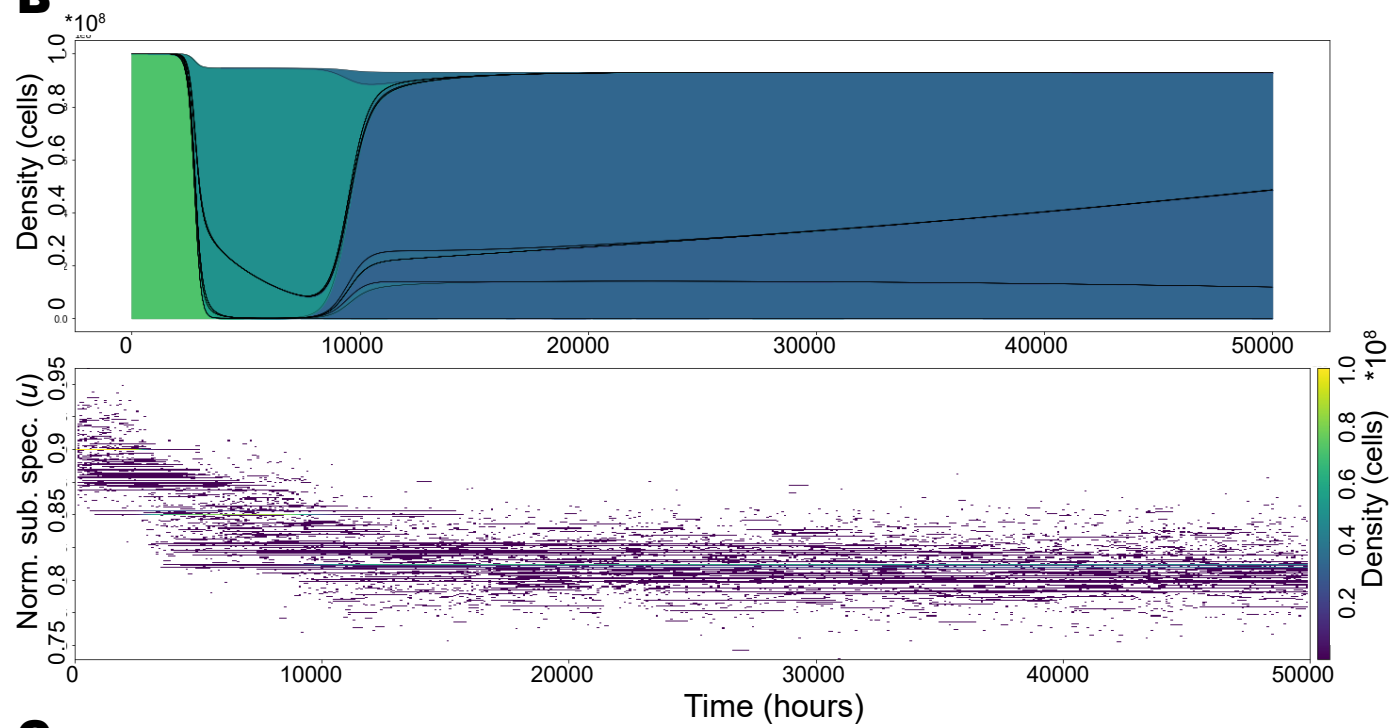

C
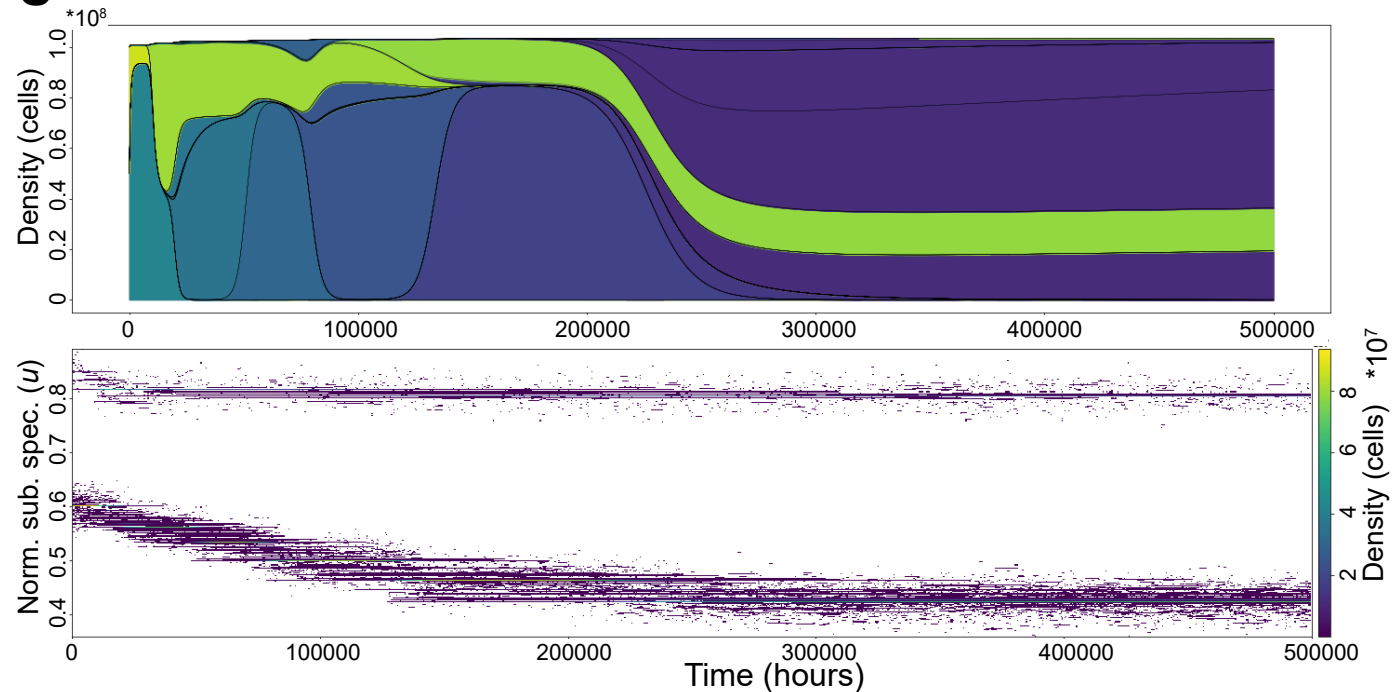

Figure A.8: Trajectories of stochastic simulations starting from different initial conditions. A and B Simulations start from a single initial phenotype, a low $(\mathbf{A})$ and high $(\mathbf{B})$ substrate specialist, to end up at a single species ESS (see Figure 5). C Simulation starts from a polymorphic population with two phenotypes, and ends up in the evolutionary stable consortium (see Figure 5). 
bioRxiv preprint doi: https://doi.org/10.1101/2021.05.18.444718; this version posted September 2, 2021. The copyright holder for this preprint (which was not certified by peer review) is the author/funder, who has granted bioRxiv a license to display the preprint in perpetuity. It is made available under aCC-BY 4.0 International license.

$\mathbf{A}$

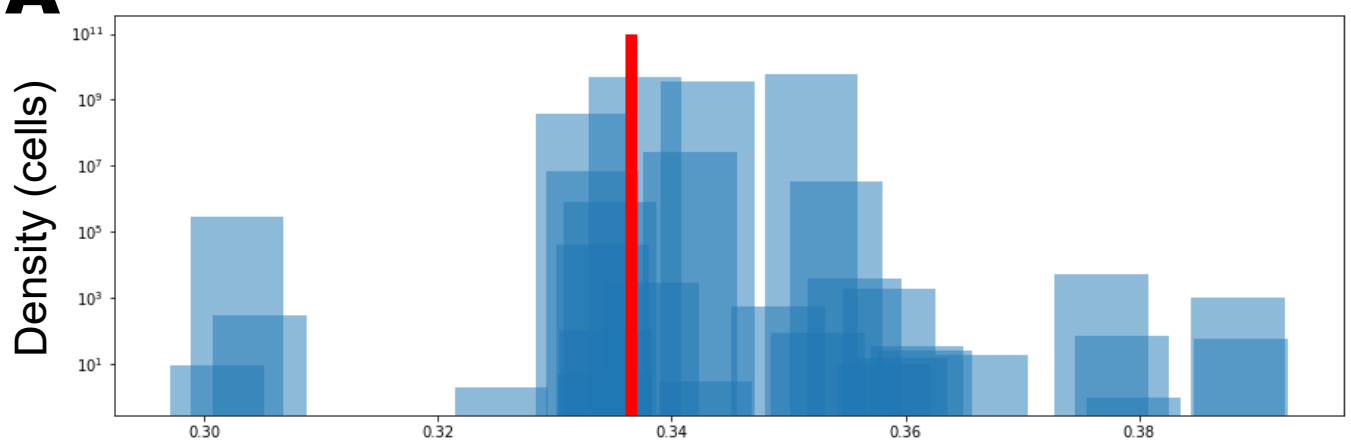

$\mathbf{B}$

norm. sub. spec. $(u)$

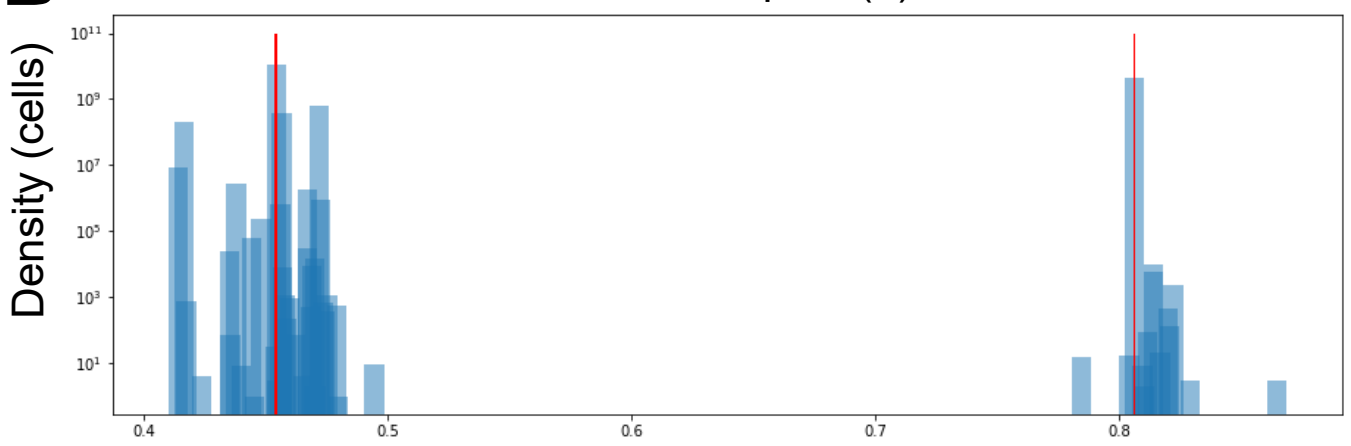

norm. sub. spec. $(u)$

Figure A.9: The red line(s) show(s) the traits used for plotting the trajectories in Figure 5 for two different examples: $\mathbf{A}$ with one dominant type and $\mathbf{B}$ with two types. 